La búsqueda de criterios orientadores en la configuración de las potestades normativas en Chile.

Kamel Cazor Aliste

Emilio Pfeffer Urquiaga

páginas $191-227$

\title{
LA BÚSQUEDA DE CRITERIOS ORIENTADORES EN LA CONFIGURACIÓN DE LAS POTESTADES NORMATIVAS EN CHILE*
}

\author{
Kamel Cazor Aliste \\ Emilio Pfeffer Urquiaga**
}

\begin{abstract}
RESUMEN
El presente trabajo busca desentrañar la técnica de reserva legal adoptada por el sistema constitucional chileno y la consecuente interacción con el poder normativo gubernamental. En nuestro país cobra especial relevancia este tópico, pues la conexión ley-reglamento se encuentra inmersa en un sistema caracterizado por la capacidad normativa variable, que no conjuga con claridad los campos competenciales y configuradores de la reserva legal y la potestad reglamentaria. De ahí que la propuesta investigativa se estructure en función de la búsqueda de criterios orientadores que permitan abordar este importante asunto, a fin de facilitar soluciones dentro de las posibilidades regulatorias que admite nuestra actual realidad constitucional.
\end{abstract}

\begin{abstract}
The present article intends to unravel the technique of legal reserve adopted by the Chilean constitutional system and its resulting interaction with the governmental normative authority. In our country, this topic is of special relevance since the connection law-regulation is immerse in a system characterized by a variable normative capacity, that doesn't clearly combine the competent and configuring fields of the legal reserve and the regulatory power. As such the research proposal is structured based on the search of guiding criteria that enable
\end{abstract}

* $\quad$ Este trabajo forma parte del Proyecto Fondecyt No 1070620 (2007-2008) titulado "La relación ley-reglamento y el control del Tribunal Constitucional en Chile", del que sus autores son, respectivamente, investigador principal y coinvestigador. Trabajo recibido con fecha 22 de enero de 2009, y aprobado el 6 de mayo de este mismo año.

** El primero es Doctor en Derecho, Profesor Asociado de Derecho Constitucional, Universidad Católica del Norte, sede Coquimbo. Correo electrónico: cazor@ucn.cl. El segundo es abogado, Profesor de Derecho Constitucional en la Universidad Diego Portales. Correo electrónico: emiliopfeffer@pfeffer.cl 
Kamel Cazor Aliste

Emilio Pfeffer Urquiaga

dealing with this important issue, in order to facilitate solutions within the regulatory possibilities that our current constitutional reality allows.

PALABRAS CLAVES

Potestades Normativas - Reserva Legal - Potestad Reglamentaria

KEY WORDS

Normative Authority -Legal Reserve - Regulatory Authority

\section{Contexto del estudio}

A fin de desentrañar la técnica de reserva legal adoptada por el sistema constitucional chileno y la consecuente interacción con el poder normativo gubernamental, se debe partir del presupuesto que el entramado jurídico-político, que afecta a ambas potestades, resultaría poco inteligible sin la utilización del acervo doctrinario del Derecho comparado. Particularmente, si la configuración de la relación ley-reglamento no es posible determinarla con la sola interpretación de los preceptos constitucionales que la regulan. En torno a la referencia al Derecho comparado, cabe recordar que es un lugar común en la doctrina nacional la constante alusión que se hace sobre la inspiración francesa que ha tenido en esta materia nuestra actual estructura constitucional (a partir de lo cual, derivan el denominado "dominio legal máximo"); sin embargo, desde ya, debemos precisar que el objetivo del constituyente no fue incorporar en estricto sentido el sistema francés en la ordenación de la relación ley-reglamento, si no que, en la práctica, conservó el diseño de la anterior Constitución, en el contexto de mantener como principio la primacía de la ley como norma de clausura del sistema normativo. Razón por la cual, resulta justificado centrar la atención en otros sistemas distintos al francés, como es el caso español o alemán.

En nuestro país cobra especial relevancia el tópico de la conexión entre la ley y el reglamento, pues tal vinculación se encuentra inmersa en un sistema caracterizado por la capacidad normativa variable, que no conjuga con claridad los campos competenciales y configuradores de la reserva legal y la potestad reglamentaria. Esto claramente es un problema que afecta el desarrollo de nuestro Estado constitucional, particularmente cuando dichas potestades normativas regulan derechos fundamentales de los ciudadanos. Cuestión especialmente significativa, toda vez que frente a la moderna actividad normativo-configuradora del Estado, conserva la Constitución su función limitadora en tales derechos subjetivos, determinando qué contenido no pueden tener esas decisiones jurídicas.

Dentro de este contexto de problematización (que, dicho sea de paso, no es exclusivo de nuestra realidad constitucional), hay que partir de la base que la labor del Tribunal Constitucional es 
La búsqueda de criterios orientadores en la configuración de las potestades normativas en Chile.

concluyente en la comprensión de los ámbitos competenciales que fija la Constitución en general y de la relación ley-reglamento en particular. Por cuanto, en la práctica, su determinación descansa en gran medida en la actividad de control que realiza dicho Tribunal, cuya doctrina jurisprudencial se ha centrado, de un modo premeditado o intuitivo, pero con poco éxito hasta ahora, en la no fácil tarea de encontrar los criterios orientadores que permitan abordar este asunto competencial y configurador de tales potestades.

Teniendo en cuenta esta perspectiva de análisis, la propuesta investigativa debe, inexorablemente, idearse en función de la búsqueda de criterios orientadores que permitan abordar este importante asunto, a fin de facilitar soluciones dentro de las posibilidades regulatorias que admite nuestra actual realidad constitucional. Llegar a una conclusión contraria, esto es, que no existan tales criterios orientadores que se sustenten en una teoría constitucional sólida, sería reconocer una debilidad teórico-regulatoria en la propia configuración de la ley y el reglamento en nuestro texto Fundamental.

En este último escenario, poco podría aportar la labor jurisprudencial del Tribunal Constitucional, con el riesgo añadido de caer en una "reserva de sentencia", que, por una parte, no incluya en su razonamiento claras premisas teórico-constitucionales, que le de un sustento argumentativo -"constitucionalmente adecuado"- a esta trascendental materia de fuentes del Derecho; o, por la otra, trate de buscar posturas de equilibrio que cada vez resultan más forzadas, a fin de tratar de cumplir el pretendido objetivo del Constituyente de lograr un sistema equitativo en la relación ley-reglamento. Razón por la cual, el objetivo central del artículo consistirá en la búsqueda y análisis de los criterios teórico-constitucionales, que pudieren aportar una precomprensión adecuada de la operatividad y alcance de las potestades normativas -que configura la Carta fundamental- del Legislativo y del Ejecutivo.

En fin, situados en este plano de razonamiento, surgen otras importantes dudas en torno a esta temática: ¿Es posible adelantar, a priori, el principio de una equilibrada relación leyreglamento, sin considerar la posibilidad constitucional que podría optar por un desequilibrio entre dichas potestades? ¿Es dable agregar, además de la jerarquía y competencia, el criterio de control? ¿Qué criterios distintivos se podrían extraer a fin de diferenciar las diversas potestades normativas? ¿A la luz de la teoría constitucional, es posible sustentar criterios orientadores sólidos en torno a la configuración de la relación ley-reglamento?

A continuación, nos adentraremos en el estudio particular de, a nuestro juicio, los más relevantes criterios orientadores, que, a la luz de claros estándares teóricoconstitucionales, permitan lograr la comprensión necesaria de la actual configuración de las potestades normativas en Chile. A partir de lo cual, además, se deducirán las principales conclusiones del trabajo. 
Kamel Cazor Aliste

Emilio Pfeffer Urquiaga

\section{Criterios orientadores como precomprensión necesaria de la configuración de las potestades normativas}

\section{II.1. Primer criterio orientador: "La necesidad de desentrañar el significado de los principios de juridicidad, legalidad y reserva de ley"}

El principio de juridicidad ${ }^{1}$ es un concepto que determina las relaciones entre el Derecho y los poderes públicos, de tal forma que toda actuación de los poderes constituidos supone la existencia de normas jurídicas que los vinculan cuando actúan y de esta forma los someten al Derecho $^{2}$. En este sentido, "debe de ponerse de relieve que el principio de juridicidad expresa siempre y necesariamente una "vinculación positiva", y no simplemente negativa, de la Administración al ordenamiento"3.

Entendido así, el principio de juridicidad "es un concepto genérico, más amplio que el de legalidad ya que incluye al principio de legalidad como una juridicidad calificada, que opera, este último, cuando la fuente jurídica que sirve de fundamento a los poderes constituidos es la ley" . Sobre el particular es importante resaltar que, como señala Adolf Merkl, el principio de legalidad presupone el principio de juridicidad, pero no necesariamente a la inversa ${ }^{5}$.

Esta visión que identifica el principio de legalidad con el principio de juridicidad, se torna significativa debido a las consecuencias que produce en el Derecho chileno. En efecto, aceptar el principio de juridicidad en tal sentido, implica considerar tres grandes alcances dentro del Estado constitucional, especialmente respecto al papel de la Administración, que se vinculan, en primer término, con el sistema jurisdiccional, en el segundo, con el principio de la división de poderes y con el ámbito de la potestad reglamentaria.

Es un hecho de la máxima importancia precisar esto, ya que a lo que usualmente se considera hoy como "principio de legalidad" administrativa, no es sólo una relación con la ley, sino con la juridicidad en su conjunto (o principio de juridicidad), y que, como expresa Manuel Rebollo, "bajo el término "reserva de ley", se esconden realmente dos significados distintos,

\footnotetext{
1 La formulación de principio de juridicidad fue realizada por primera vez por Adolf Merkl, en su obra Teoría General del Derecho Administrativo, (1953, Madrid, Editorial Revista de Derecho Privado, pp. 212 y sig.), y es seguida por la doctrina española entre otros por Ignacio De Otto, 1988, Derecho constitucional. Sistema de Fuentes. Ariel, Barcelona, p. 157.

2 Kamel Cazor, 2002 La sumisión a Derecho de los actos y disposiciones del Presidente de la República, Tomo I, Santiago, Universidad Central de Chile, p. 58.

Manuel Rebollo, 1991 "Juridicidad, legalidad y reserva de ley como límites a la potestad reglamentaria del Gobierno", en Revista de Administración Pública, Núm. 125, p. 67.

Cazor, La sumisión, cit. nota n. 2, p. 58.

Merkl, Teoría, cit. nota n. 1, p. 215.
} 
La búsqueda de criterios orientadores en la configuración de las potestades normativas en Chile.

uno relativo a toda la actuación administrativa y otro sólo a su potestad reglamentaria, de los que el primero encaja con lo que nosotros hemos situado en el principio de legalidad". ${ }^{6}$ Del mismo modo, ya que son planos de verificación y conocimiento disímiles, esta perspectiva es relevante a fin de diferenciar las cuestiones meramente legales (principio de legalidad), de los asuntos de estricta relevancia constitucional, como acontece, en este último caso, con la vinculación entre la reserva legal y la potestad reglamentaria. En fin, como bien sintetiza Joaquín Torno Mas, "el cumplimiento de la reserva legal determina la relación entre la Ley y el Reglamento, por lo que no debe identificarse con el principio de legalidad que supone la vinculación de la Administración a una norma previa, norma que atribuye a la Administración su potestad de ejecución (...) en consecuencia -prosigue-, la relación Ley-Reglamento, como poder de formación, debe partir de unas especiales coordenadas (...) la Administración, al reglamentar, adquiere un papel diverso a la Administración que ejecuta una norma, comenzando por el hecho de que la potestad de reglamentar la recibe la Administración de la Constitución y la Ley se limita a fijar su alcance material".?

En cuanto a las repercusiones en el sistema jurisdiccional, Juan Alfonso Santamaría Pastor expresa: "El auténtico freno de la potestad reglamentaria no es ya la ley, sino el sistema jurisdiccional, todavía no conectado (o no conectado del todo) a la correa de transmisión de los partidos, y cuyos parámetros de control de los reglamentos son, cada vez con mayor intensidad, la Constitución y los principios generales, mucho menos adaptables que la ley a los intereses concretos del gobierno" . Concebir de este modo el principio de juridicidad como la sujeción de los poderes constituidos al Derecho, significa que esta vinculación es en última instancia una superación al clásico concepto del principio de legalidad (sometimiento a normas de rango legal), que se expresa en un sentido multidireccional, desde la perspectiva genérica que comprende la juridicidad. Así, "se asegura un parámetro jurídico de verificación más amplio, de sometimiento pleno al Derecho; con ello, se realzan también los criterios orientadores y, por ende, la importancia en el papel de los jueces" ". Dicho en otros términos, esta nueva subordinación de los poderes públicos encuentra su parámetro en lo constitucionalmente adecuado, que también determina y condiciona los mecanismos verificadores de control jurídico, los cuales, en última instancia, siempre responden al tipo concreto de la Constitución ${ }^{10}$. En este contexto, como los valores superiores y los principios constitucionales dotan de sentido y

Rebollo, "Juridicidad", cit. nota n. 3, p. 65.

Joaquín Torno Mas, 1983, "La relación entre la ley y el reglamento: reserva legal y remisión normativa. Algunos aspectos conflictivos a la luz de la jurisprudencia constitucional", en Revista de Administración Pública, $\mathrm{n}^{\circ} 100-102$, p. 506.

8 Juan Alfonso Santamaría Pastor, 1988, Fundamentos de Derecho Administrativo I, Madrid, Editorial Centro de Estudios Ramón Areces, p. 738.

Cazor, La sumisión, cit. nota n. 2, p. 59.

Cazor, La sumisión, cit. nota n. 2, p. 59. 
Kamel Cazor Aliste

Emilio Pfeffer Urquiaga

cierran el ordenamiento, desempeñan una función esencial como criterios guías de la decisión de los jueces; los cuales, en su labor de conformación con el Derecho, lo deben descubrir y no inventar ${ }^{11}$. Así, se podría enjuiciar la actividad discrecional de la Administración a la luz de tales principios o valores generales, en donde la actuación de dicha potestad ha de ajustarse a las exigencias de éstos; como acontece, por ejemplo, en algunos supuestos que pueden significar arbitrariedad en el ejercicio de la potestad reglamentaria: apreciación falsa de los hechos, ruptura del principio de igualdad, falta de proporcionalidad, desviación de poder, vulneración de los derechos fundamentales, irrazonabilidad, etc.

Respecto al segundo alcance anteriormente mencionado, la aceptación del principio de juridicidad significa que, dentro de un Estado con división de poderes, se "niega que esté en mano de uno de ellos, el Legislativo, la emanación de todas las normas atributivas en favor de la Administración; que las competencias de ésta hayan de derivar, todas ellas y siempre, de la Ley; la Administración contará, por tanto, con justificaciones jurídicas de su actuación distinta de la Ley"12. Razón por la cual, la Administración, en esta nueva relación de subordinación, que rompe su clásica relación con la ley, alcanza un ámbito material más amplio de acción de su potestad normativa, y, como ha puesto de relieve Francisco Rubio Llorente, la equiparación de los dos principios (legalidad-juridicidad) hace que quede en entredicho la primacía de la ley del Parlamento como fuente del Derecho, limitada sólo por la Constitución; entender el principio de juridicidad como sujeción a norma jurídica, u ordenamiento jurídico en general, sin concreciones y sea cual sea su forma y origen, hace que sea fuente de validez cualquier otro precepto, aunque no se refiera a la ley emanada del Poder Legislativo ${ }^{13}$.

De lo anterior, es posible deducir dos importantes consecuencias:

a. Es dable apreciar en nuestro sistema constitucional, un cierto rompimiento con el dualismo tradicional entre ley y reglamento, ya que se presenta al Gobierno como un ente con legitimidad propia, portador del liderazgo político, y la Administración pública realizadora de esa política. En este contexto, puede darse cabida no sólo a un papel legitimador de la ley como "presupuesto" (vinculación positiva), sino también como un "límite" (vinculación negativa) que determine un margen de acción más discrecional de parte del órgano Ejecutivo. Así, por ejemplo, es posible constatar, aunque no muy bien delimitada, una reserva de Gobierno, cuya definición se origina en una autonomía constitucionalmente derivada, especialmente frente al Legislativo; presentando al Jefe del Estado como un ente autónomo y con legitimidad propia, que extiende su autoridad de dirección política -

\footnotetext{
11 Manuel Aragón, 1989, Constitución y Democracia, Madrid, Tecnos, pp. 77-78.

Rebollo, "Juridicidad", cit. nota n. 3, p. 71.

Francisco Rubio Llorente, 1997, La Forma del Poder (Estudios sobre la Constitución), Madrid, Centro de Estudios Constitucionales, pp. 300-306.
} 
La búsqueda de criterios orientadores en la configuración de las potestades normativas en Chile.

de acuerdo con la Constitución y las leyes- a todo cuanto tiene por objeto la conservación de los intereses nacionales (art. 24).

b. Entender el principio de juridicidad de esta forma supone, igualmente, otorgar a la potestad reglamentaria igual legitimidad que la potestad legislativa en las materias que no sean objeto de reserva material específica de ley, sin perjuicio de lo que señalaremos más adelante respecto a la regulación normativa de los derechos fundamentales. Así de este modo, el ejercicio de la potestad reglamentaria encuentra un límite, cuando la Constitución haya establecido que ciertas materias quedan reservadas a la ley, atribuyéndose a esta reserva un monopolio que acota negativamente la regulación legislativa; expresado en otros términos, la potestad reglamentaria debe ser contemplada en el conjunto del ordenamiento jurídico y en relación con otras fuentes del mismo, sin olvidar el principio de jerarquía normativa y la reserva constitucional de ley que fija su esfera competencial de regulación. ${ }^{14}$ Sin embargo, como se verá a continuación, el papel de la reserva de ley en el Estado democrático y su ligazón con los derechos fundamentales, debilitan la intensidad de los poderes normativos de la Administración en esta esfera. Cuestión que dificulta la funcionalidad normativa entre órganos que poseen legitimidad democrática, como es el caso del Congreso Nacional y el Presidente de la República.

\section{II.2. Segundo criterio orientador: 'La exigencia de definir la función de la reserva legal en el Estado constitucional y democrático y su vinculación con los derechos fundamentales"}

Prosiguiendo el estudio de los criterios teórico-constitucionales y siguiendo a Conrado Hesse, hay que partir del "reconocimiento de que la Constitución de una concreta comunidad política, su contenido, la singularidad de sus normas y sus problemas han de ser comprendidos desde una perspectiva histórica. Sólo la conciencia de esta historicidad -prosigue- permite la comprensión total y el enjuiciamiento acertado de las cuestiones jurídico y políticoconstitucionales. Esto es algo que no puede ofrecer una teoría general y abstracta insensible, que no enmarque la Constitución en la realidad político-social y sus peculiaridades históricas. Tampoco la comprensión histórica puede prescindir sin más de la justificación y de la configuración teórica. Pero semejante teoría -concluye- ha de estar referida al ordenamiento constitucional concreto y a la realidad que la Constitución está llamada a ordenar"15.

Reflexión que puede tener cabida tanto para la Ley Fundamental de Alemania (cual es

Cazor, La sumisión, cit., nota n. 2, p. 61.

Conrado Hesse, 2001, "Constitución y Derecho Constitucional”, en AAVV, Manual de Derecho Constitucional, Madrid-Barcelona (segunda edición), Marcial Pons, Ediciones Jurídicas y Sociales, p. 1. 
Kamel Cazor Aliste

Emilio Pfeffer Urquiaga

precisamente la perspectiva que toma Hesse) como de la Constitución chilena actual, y de la cual se pueden destacar dos matices consecuenciales: a) la normatividad de la Constitución se debe enmarcar en la realidad político-social que rige y sus particularidades históricas; y b) también debe considerarse la justificación y configuración teórica referente a tal aspecto. Todo ello, sin olvidar que se está en presencia de un problema jurídico-constitucional, cuestión que obliga a la comunidad científica a encontrar nuevas vías e instrumentos técnicos en apoyo a la fuerza normativa de la Constitución ${ }^{16}$. Sobre todo si se está abordando un tema tan relevante como es la relación ley-reglamento (vinculación, no hay que olvidar, de naturaleza esencialmente conflictiva). Como indica Luís Villacorta, resaltando la importancia de esta temática, "nos movemos, pues, en el ámbito de un tema clásico desde al menos finales del siglo pasado [XIX], el de las relaciones entre la Ley y el Reglamento, pero que ha cobrado de nuevo actualidad (...) uno de los problemas fundamentales que se plantean a la investigación-continúa- es el de determinar las relaciones entre Constitución y Ley y entre ésta y el Reglamento, o expresado en otra forma, determinar qué concepto de Ley es el adecuado a las nuevas coordenadas constitucionales, basadas en los principios Democrático y de Derecho, por medio de los cuales el legislador está vinculado jurídicamente"17.

Existe claramente un correlato entre la noción de reserva legal y cómo se define la ley, y a partir de esto último se articulan las restantes fuentes, especialmente el reglamento. Sin embargo, en las actuales circunstancias del Estado democrático, no resulta sencillo redefinir el papel de la reserva, cuyo nacimiento histórico, cabe recordar, buscaba dar respuesta a la necesidad de "limitar el ámbito de actuación de un Poder Ejecutivo, todavía monárquico, frente a un Poder Legislativo, en el que toma cuerpo la representación popular, lo que lleva, en la Monarquía dualista, a una delimitación material de la competencia del Parlamento (libertad y propiedad) y al principio de reserva, o requerimiento de una Ley del Parlamento para las normas que afecten a dicho ámbito material". ${ }^{18}$ Distinguir esta diferencia resulta esencial para vislumbrar los problemas actuales que se presentan en el sistema de fuentes, por cuanto la complementariedad o contraste entre sus distintos componentes, "hace que cualquier modificación en uno de ellos produzca alteraciones en la función de los restantes" $"$.

Cuestión que, sobre todo, obliga a armonizar o coordinar sus actuaciones, en pos de las finalidades propias de los Estados democráticos ${ }^{20}$. Circunstancia que hace imperioso redefinir la función de la reserva en el Estado constitucional, y que obliga a enfrentarse a la trascendental relación entre Constitución y democracia, y la intrincada vinculación de ambos con los derechos

Javier Pérez Royo, 2007 (quinta edición), Las fuentes del Derecho, Madrid, Tecnos, p. 39. Luís Villacorta, 1994, Reserva de ley y Constitución, Madrid, Editorial Dykinson, p. 21. Juan Encinar, prólogo al libro de Luís Villacorta, Reserva, cit. nota n. 17, p.12.

Encinar, Reserva, cit. nota n. 17, p.13.

Encinar, Reserva, cit. nota n. 17, p.13.
} 
La búsqueda de criterios orientadores en la configuración de las potestades normativas en Chile.

fundamentales. Desde esta perspectiva, se debe ser muy cuidadoso al momento de argumentar interpretaciones extensivas de la reserva legal, lo que lejos de ampliar las competencias del legislador, muchas veces conducen a dificultar la necesaria actuación de la Administración. Sobre todo, si se tiene en cuenta que hoy la reserva de ley en materia de derechos fundamentales se dirige "contra" el legislador ${ }^{21}$; en donde ya no es sólo una materia que debe sustraerse de la potestad reglamentaria, o el de evitar que se le recorten competencias al Poder Legislativo, si no de obligar a este último a regular y desarrollar tales derechos subjetivos, asegurando no sólo el contenido esencial de los mismos, sino también sus garantías para hacer posible realmente la existencia del derecho fundamental.

De ahí que exista la necesidad de redefinir la función de la reserva en el Estado constitucional y democrático, y su vinculación con los derechos fundamentales.

Como bien es conocido, el fundamento de la técnica de la reserva de ley se encuentra, actualmente, en el principio democrático y en la garantía del pluralismo político (especialmente como garantía de las minorías). Con lo cual, se pretende reservar ciertas materias a la forma de ley en el entendido de que la intervención de los representantes de los ciudadanos, en un proceso legislativo caracterizado por los principios de contradicción y publicidad, produce una norma con mayor legitimidad que las demás. Desde esta perspectiva, lo que legitima esencialmente a la ley, no es su contenido, sino su procedimiento de elaboración, es decir, la ley en un sentido formal. Sin embargo, no hay que olvidar que también es esencial para cualquier Estado constitucional que todo procedimiento democrático (democracia formal) esté limitado materialmente por los derechos fundamentales (democracia sustancial) ${ }^{22}$. Produciéndose la peculiar relación entre tales derechos subjetivos y la democracia, que Robert Alexy sintetiza por vía de "dos constataciones opuestas, que rezan así: 1) Los derechos fundamentales son profundamente democráticos. 2) Los derechos fundamentales son profundamente antidemocráticos" ${ }^{23}$; por ello, lograr la reconciliación del principio democrático con los derechos fundamentales, constituye un presupuesto básico para lograr las condiciones de cooperación social justa ${ }^{24}$.

Tarea que no está exenta de discrepancias para el intérprete constitucional, y que es posible

21 Encinar, Reserva, cit. nota n. 17, p.15.

22 Hay que hacer presente, que algunos autores consideran "al menos inoportuno, por ser generador de confusiones, cualquier uso del adjetivo "sustancial" para el sustantivo democracia". No obstante que, Luigi Ferrajoli hace de la noción de democracia sustancial uno de los pilares de su teoría jurídico-política, pero dicha noción la plantea como equivalente a la de Estado de Derecho dotado de efectivas garantías, tanto liberales como sociales: concebida de esta manera, la noción de democracia sustancial no sustituye, sino que acompaña a la de democracia formal (Michelangelo Bovero, 2002, Una gramática de la democracia, Madrid, Trotta, pp. 44-46).

23 Robert Alexy, 2005, "Los derechos fundamentales en el Estado constitucional democrático", en AAVV Neoconstitucionalismo(s), Madrid, Trotta, p. 38.

24

Alexy, "Los derechos", cit. nota n. 23, p. 40. 
Kamel Cazor Aliste

Emilio Pfeffer Urquiaga

constatar en los diversos razonamientos que se dan de la reserva de ley, tanto en la doctrina como en la jurisprudencia. Al respecto, algunos autores encuentran el origen de estas diferencias en las ideas políticas de los intérpretes, que responden muchas veces a distintas concepciones sobre la sociedad, las relaciones entre ésta y el Estado, y las funciones que le corresponden a este último. ${ }^{25}$ Así, por ejemplo, en el Derecho español, dentro de un paradigma liberal se deben incluir a los autores que interpretan de forma especialmente rígida y expansiva los elementos propios del Estado de Derecho, mientras que dentro de un paradigma social se agrupan a los autores que flexibilizan la interpretación de los elementos del Estado de Derecho teniendo en cuenta la perspectiva del Estado social; todo lo cual, sin duda, va a tener consecuencias tanto en la comprensión de la ley como en la comprensión del reglamento. ${ }^{26}$ Dentro de este parámetro, como se verá con más detalle más adelante, la reserva de ley cumpliría, según el paradigma liberal, la función de garantía frente a intervenciones de los poderes públicos en los ámbitos de libertad de los ciudadanos, o como garantía del pluralismo democrático, según el paradigma social. ${ }^{27}$

Se coincide, por las razones antes señaladas, con José María Baño León, en el sentido de que la interpretación constitucional tiene tal vez en la reserva de ley su desafío más permanente, la referencia a la naturaleza conflictiva de las relaciones entre Ley y Reglamento, o la virtualidad de la controversia acerca de la extensión e intensidad de los poderes normativos de la Administración. ${ }^{28}$ Asimismo, es certera la idea de este mismo autor, acerca de la repercusión que para la reserva de ley implica la institucionalización de la jurisdicción constitucional "que no justifica pero sí explica la importancia creciente de la reserva de ley". ${ }^{29}$ La garantía de la reserva legal, en consecuencia, claramente es un problema actual en el ámbito del Derecho constitucional, ya sea en lo referente a sus aspectos teóricos, como del punto de vista de la práctica jurídica. ${ }^{30}$ Por ello, no se debe pasar por alto, como indica Carlos Peña, "que uno de los aspectos claves de la protección de los derechos subjetivos se relaciona con el modo en que se concibe, en la práctica constitucional del caso, la relación entre derechos, por una parte, y principio de legitimidad democrática, por otra (...) Así según cuál sea la relación que entre ambos términos resulta trazada, es distinto el fundamento y el alcance que revisten los controles de constitucionalidad de los que, como es obvio, forman parte los mecanismos de protección (...) Igualmente influyen en ello el modo de concebir el razonamiento práctico y el papel que el sistema jurídico del caso asigne a los jueces". ${ }^{31}$

\footnotetext{
25 Eduardo Melero, 2004, "La flexibilidad de la reserva de ley", en Revista Jurídica Universidad Autónoma, Madrid, Dykinson, p. 110.

26 Melero, "La flexibilidad", cit. nota n. 25, pp. 110 y 128.

Melero, "La flexibilidad", cit. nota n. 25, p. 128.

José María Baño León, 1991, Los límites constitucionales de la potestad reglamentaria, Madrid, Civitas, pp. 19-24.

Baño, Los límites, cit. nota n. 28, p. 75.

Villacorta, Reserva, cit. nota n. 17, p. 20.

Carlos Peña, 1996, Práctica Constitucional y Derechos Fundamentales, Santiago, Corporación Nacional de Reparación y Reconciliación, Colección de Estudios N 5, p. 79.
} 
La búsqueda de criterios orientadores en la configuración de las potestades normativas en Chile.

El contexto central de la temática de este apartado, impide entrar en la trascendental controversia de la relación entre democracia y constitucionalismo (derechos fundamentales) ${ }^{32}$, motivada a raíz de "la dificultad para admitir desde los parámetros de una teoría política democrática que se impongan límites constitucionales a la capacidad de deliberación de los ciudadanos y al poder de decisión de las mayorías" ${ }^{33}$. No obstante, resulta conveniente citar brevemente las perspectivas de algunos autores, que ponen en evidencia la dicotomía entre constitucionalismo y democracia.

En primer término, Neil MacCormick expresa que "la democracia funciona sólo donde hay alguna forma de orden constitucional bien establecido", desde esta perspectiva -continúa"el constitucionalismo es un requisito previo a la democracia", que hace posible y viable esta última; por ello no se trata de una democracia pura y simple, sino de una democracia cualificada por el constitucionalismo ${ }^{34}$. Sin embargo, a la luz de nuestra peculiar experiencia de constitucionalismo, resulta poco sustentable -y hasta riesgosa- la idea de que el constitucionalismo sea un prerrequisito de la democracia y de que ésta no representa un ideal autosuficiente. Motivo por el cual, nuestro razonamiento debe ir mucho más allá, ya que es un hecho ineludible que la democracia, como algo se ha visto, se trata de un principio configurador de naturaleza material, cuyo procedimiento esencialmente busca el desarrollo y garantía de los derechos y libertades fundamentales, entendiendo por tales a aquellos asociados al propio principio democrático, en particular, como al resto de los derechos fundamentales, en general.

Desde este plano, en segundo término, se debe mencionar que la democracia constitucional se trata necesariamente de una democracia sustancial, ya que, citando a Jeremy Waldron, "existe un congruencia natural entre los derechos y la democracia" (...) "no podemos apelar-continúaa ninguna oposición fundamental entre la idea de democracia y la idea de derechos individuales [por ejemplo] como base para criticar la práctica de control judicial de constitucionalidad de las leyes como la de los Estados Unidos. No existe tal oposición fundamental. Si hay una objeción democrática al control de constitucionalidad, debe estar también basada en derechos. $\mathrm{Y}$-concluye- no podemos sostener esta objeción a menos que estemos preparados para responder algunas cuestiones difíciles sobre cómo se supone que los derechos deben ser protegidos en un sistema de toma de decisiones democráticas". ${ }^{35}$ Sería poco sostenible y realista, por lo tanto, cualquier teoría de la Constitución, cuyo ideal constitucional se convierta en un freno para el

32 Jon Elster/Rune Slagstad, 1999, Constitucionalismo y democracia, México, Fondo de Cultura Económica; y Hans Peter Schneider, 1991, Democracia y Constitución, Madrid, Centro de Estudios Constitucionales.

33 Antonio Peña Freire, 2003, "Constitucionalismo Garantista y Democracia", en Revista Crítica Jurídica, №22, p. 32 .

34 Neil MacCormick, 1988-89, "Constitucionalismo y democracia", en Anuario de Derechos Humanos, Universidad Complutense de Madrid, $\mathrm{N}^{\circ}$ 5, p. 380. Jeremy Waldron, 2005, Derechos y desacuerdos, Madrid, Marcial Pons, pp. 337 y 338. 
Kamel Cazor Aliste

Emilio Pfeffer Urquiaga

proceso democrático, ya que, a largo plazo, afectaría la propia sustancialidad de la Carta fundamental.

Como es fácil apreciar, no se trata para nada de un tema pacífico, muy bien sintetizado en las ideas de José Joaquín Gomes Canotilho. Señala este autor: "La dicotomía "demócratas puros"/“constitucionalistas puros" no significa en modo alguno que los "constitucionalistas" no sea "demócratas" y los "demócratas" no sean "constitucionalistas". El constitucionalismo considera fundamental el proceso democrático y la teoría democrática reconoce la importancia de los derechos fundamentales garantizados en la Constitución. La divergencia básica radica en la forma de proteger estos derechos y los bienes constitucionales a ellos inherentes. Los "demócratas puros" creen en la primacía del autogobierno democrático y en el proceso democrático como la forma de asegurar la protección de las libertades y derechos de las personas. Los "constitucionalistas" toman el proceso político como base de las políticas públicas en relación a los derechos, pero el proceso político no es suficiente para avalar la justeza de esas políticas" ${ }^{36}$.

Ahora bien, como ya hemos destacado, la temática de las potestades normativas y su configuración, ponen de relieve la forma de cómo se articulan las fuentes del Derecho, especialmente la relación ley-reglamento. De ahí que resulte imprescindible buscar criterios de equilibrio, a fin de hacer funcional los elementos normativos que componen el sistema de fuentes, cuestión que no está ajena a controversias y en la cual, como asimismo se ha adelantado, están presentes no sólo las ideas jurídicas de los intérpretes constitucionales, sino también sus ideas políticas, que se manifiestan, por ejemplo, en el ya mencionado paradigma liberal y en el paradigma social; es decir, "al ser una cuestión que delimita las fronteras entre la ley y el reglamento, no sólo se está refiriendo a una distinción químicamente jurídica, sino que, de sobre manera, política" ${ }^{37}$ Modelos que, a su vez, tienen repercusiones en la función, ámbito e intensidad de la reserva legal y explican los diversos razonamientos que se dan en torno a ella.

De ahí que hagamos una breve referencia a estos paradigmas, sistematizándolos a partir de tres aspectos: la función que cumple la reserva; el ámbito de las materias que se encuentran reservadas; y la intensidad normativa que la regulación legal debe tener en las materias reservadas.

Desde un paradigma liberal, la función de la reserva está relacionada con la garantía de los derechos de los ciudadanos (téngase en cuenta que, en su origen liberal, la reserva de ley en materia de propiedad y libertad, definida por Otto Mayer, cumplía una función equivalente a 
La búsqueda de criterios orientadores en la configuración de las potestades normativas en Chile.

una declaración de derechos, declaración que no recogía la Constitución del Reich de 1871) ) $^{38}$. Desde el paradigma social, en cambio, "se concibe la función de la reserva de ley como garantía de que la regulación de determinadas materias se realice a través del procedimiento legislativo, asegurando el pluralismo democrático frente a una posible expansión ilimitada de la potestad reglamentaria del Gobierno", ya que la calidad procedimental de las leyes es diferente que las del reglamento. ${ }^{39}$

Si nos situamos, ahora, en el ámbito de la reserva de ley, desde el paradigma liberal "se mantiene la existencia de una reserva de tipo general", y abarca todos los actos de poder público que incidan de modo limitativo en la esfera jurídica o personal de los ciudadanos, esto es, todo aquello que concierna al libre desarrollo de la personalidad, y, como consecuencia de ello, no se pueden dictar reglamentos independientes que afecten a la libertad y a la propiedad. ${ }^{40}$ La excepción a esta concepción genérica de la reserva está en Francisco Rubio Llorente, ya que su visión liberal se manifiesta en su concepción amplia del principio de legalidad para determinar la relación entre ley y reglamento, especialmente en torno al mantenimiento del poder del Parlamento y la negación de los reglamentos independientes. ${ }^{41}$ Sin perjuicio, de que este mismo autor, como ya se mencionó, al equiparar los principios de legalidad y juridicidad hace que quede en entredicho la primacía de la ley del Parlamento como fuente del Derecho, limitada sólo por la Constitución. Al contrario, "el paradigma social niega la existencia de una reserva de ley genérica", y parte del extenso y complejo sistema de reservas específicas que recoge la Constitución española. ${ }^{42}$

Baño, Los límites, cit. nota n. 28, pp. 20 y 44.

Melero, "La flexibilidad", cit. nota n. 25, pp. 110 y 114.

Melero, "La flexibilidad", cit. nota n. 25, pp. 111-112. Según Eduardo García de Enterría en el sistema español existe una reserva general en las materias relativas a la «libertad y la propiedad» (que entendido en su expresión moderna, constituye una reserva que se deriva del derecho fundamental al «libre desarrollo de la personalidad»), y todo lo que tenga que ver con ellas el reglamento sólo tiene cabida siempre que se produzca una habilitación legal, lo que excluye al reglamento independiente como norma alternativa a la ley; no cabría hablar, pues, ni de reserva reglamentaria, ni tampoco de una reserva de Administración. En síntesis, según este autor, el principio de la primacía de la ley se encuentra en estrecha relación con el principio de la reserva material, ya que el establecimiento de ésta constituye un principio montado en beneficio de aquélla y no en su perjuicio, lo que excluye un reparto material del campo normativo (1995, Curso de Derecho Administrativo, Tomo I, Madrid, Civitas, pp. 230-231). A su vez, Juan Alfonso Santamaría Pastor, pone de relieve que en ningún caso la potestad reglamentaria independiente constituye un ámbito reservado, sino eventual y condicionado. Y dice: "la existencia de un amplio conjunto de materias reservadas a la ley no implica (al contrario de lo que sucede en Francia) que los restantes campos posibles de actuación normativa queden reservados al reglamento. No hay prohibición ni límite impuesto a la ley, que puede extravasar con entera libertad las materias que constitucionalmente le están reservadas, apoderándose de cualquier otro campo (salvo, insistimos, las concretas excepciones que la Constitución española señala) y expulsando total o parcialmente del mismo, si le place, a la normativa reglamentaria (primacía objetiva de la ley)" (Santamaría, Fundamentos, cit. nota n. 8, p. 790).

Rubio, La forma, cit. nota n. 13, pp. 300-306.

Melero, "La flexibilidad", cit. nota n. 25, p. 115. Cabe recordar a Ignacio De Otto, quien niega la existencia de una reserva general de ley en la Constitución española y sólo reconoce reservas parciales sobre determinadas 
Kamel Cazor Aliste

Emilio Pfeffer Urquiaga

En cuanto a la intensidad de la reserva, "el paradigma liberal considera que, en las materias reservadas, los reglamentos se encuentran sometidos a la ley de una manera especialmente intensa, concibiendo al reglamento como complemento indispensable de la ley, es decir, debe regular todo lo indispensable para garantizar la aplicación de la ley, pero no puede ir más allá de lo estrictamente indispensable". ${ }^{43}$ A su vez, "el paradigma social no difiere demasiado del paradigma liberal en cuanto a la intensidad de la reserva aunque, en línea de principio, reconoce un mayor margen al reglamento en materias reservadas"; también se ha señalado que en las reservas relativas la potestad reglamentaria puede introducir opciones políticas, como también modula la intensidad de la reserva en función de la materia, y a mayor grado de afectación de la regulación de un derecho fundamental menores posibilidades de remisión de la ley al reglamento. ${ }^{44}$

Pasando al ordenamiento chileno, no hay que olvidar, como se ha mencionado en otro trabajo, que en nuestro país "la relación entre constitucionalismo y democracia se ha ido desarrollando durante nuestra vida republicana en base a la dicotomía entre ficción y realidad, cuyo patrón de autoridad predominante ha sido el legal-constitucional, diluyéndose en tal normatividad la titularidad de la soberanía estatal, privilegiándose sobre todo la estabilidad (...) De esta forma, resulta necesario reconducir nuestra teoría de la Constitución -y su correspondiente práctica- a través del principio democrático, a fin de enmendar, por esta vía, el

materias. En este sentido, para este autor, la técnica de reservas concretas sirve para determinar las relaciones entre ley y reglamento, en la medida que en aquellas materias donde no existe reserva de ley es posible que el ejecutivo ejerza su poder reglamentario independiente ad extra. Por ello este autor concluye señalando lo siguiente: "es cierto que según el derecho positivo español la potestad reglamentaria de la Administración está sujeta a límites más o menos amplios según los casos, pero esas diferencias no obedecen en modo alguno a cualidades intrínsecas de los objetos sobre los que verse el reglamento, sino a disposiciones constitucionales que establecen en ciertas materias reservas en favor del legislador y circunscriben así la potestad reglamentaria, sin que las diferencias resultantes coincidan con las que se producirían de aplicarse el criterio de clasificación que distingue los reglamentos administrativos de los jurídicos" (De Otto, Derecho, cit. nota n. 1, p. 219; ver especialmente en su capítulo XI, pp. 214 y siguientes, donde desarrolla su tesis sobre la potestad reglamentaria independiente del ejecutivo en la Constitución española). Además en este sentido Luís María Díez-Picazo resume certeramente esta tesis de Ignacio De Otto, y dice: "Esta sugestiva tesis se fundamenta, en última instancia, en un rechazo del argumento central de la doctrina mayoritaria, según el cual la interdicción de los reglamentos independientes en materias no organizativas deriva de la reserva general del artículo 53.1 CE; esto es, procede de la natural fuerza expansiva de los derechos fundamentales en un Estado de Derecho, de suerte que toda regulación de relaciones intersubjetivas afecta, de un modo u otro, a derechos fundamentales, coincidiendo así la reserva del citado artículo 53.1 CE con la vieja cláusula germánica de libertad y propiedad. Frente a esto, subraya De Otto el tenor literal del artículo 53.1 CE, que reserva a la ley tan sólo la regulación del ejercicio de tales derechos y libertades, a la vez que pone de relieve la íntima conexión existente entre la mayoría parlamentaria y Poder Ejecutivo -hoy el auténtico conflicto es el que media entre mayoría y oposición- y la consiguiente legitimación democrática del Gobierno." (1990, "Concepto de ley y tipos de leyes", en AA. VV. El Parlamento y sus transformaciones actuales, como editor Ángel Garrorena, Madrid, Tecnos, p. 154).

43 Melero, "La flexibilidad", cit. nota n. 25, pp. 112-113.

44 Melero, "La flexibilidad", cit. nota n. 25, pp. 115-116. 
La búsqueda de criterios orientadores en la configuración de las potestades normativas en Chile.

rumbo de nuestra Constitución histórica y la peculiar forma de constitucionalismo que se ha generado (....) En los años venideros, el gran desafío del Ordenamiento Fundamental chileno se debe traducir en lograr compatibilizar democracia y constitucionalismo, cuestión que no ha ocurrido hasta el día de hoy en nuestra historia constitucional". ${ }^{45}$ Desde esta perspectiva, estamos viviendo una transición en el modelo teórico-jurídico de nuestro constitucionalismo, en donde existe la necesidad de proseguir en la elaboración de nuevos principios, categorías y conceptos, sin olvidar que muchos de los que están hoy vigentes son categorías técnicas y construcciones dogmáticas, pensados y adecuados a otras realidades y tiempos. Sobre todo hay que tener presente, que el Derecho constitucional chileno, al margen de su condicionamiento histórico ya mencionado, aún está haciendo frente al tránsito de un Estado autoritario a un Estado constitucional y democrático.

Dentro de este contexto de influencia -más político que jurídico- y no del todo sistematizadas, la doctrina nacional ha elaborado diversas teorías, que muy bien Carlos Carmona las circunscribe en un nuevo estadio de la relación ley-reglamento, toda vez que antes era un asunto que se discutía en torno a la legitimidad de la regulación reglamentaria, ahora la discusión se centra en determinar cuál es el margen o el ámbito de su intervención (más precisamente la intensidad o profundidad de la ordenación), es decir, cuánta regulación le es posible al reglamento; ${ }^{46}$ en este último punto, prosigue este mismo autor, existe controversia en torno al límite de esta tarea. En efecto, para unos -indica- (posición "finalista"), el rol central del reglamento es la ejecución de la ley, es decir, el cometido del reglamento es aplicar e implementar la norma legal, el reglamento complementa la ley para su mejor ejecución. Para otros (posición del "parámetro estricto"), en cambio, el reglamento sólo puede desarrollar lo ya legislado, la potestad reglamentaria es una atribución de aplicación, no de complementación, su función es pormenorizar, sin alterar, completar o complementar la ley, es decir, ejecuta la ley, pero no es ley; es ésta la que establece su grado de maniobra. ${ }^{47}$

Para determinar el grado de intervención del reglamento en la regulación, se han planteado tres teorías en la doctrina chilena: la teoría del complemento indispensable, la teoría de la razonabilidad técnica y la teoría de la intensidad de la reserva.

Respecto a la teoría del complemento indispensable, ésta se plantea dentro de una relación de colaboración entre la potestad reglamentaria y la potestad legislativa, y se concibe el reglamento como una norma destinada a regular todo lo indispensable a fin de garantizar la

Kamel Cazor, 2007, "Constitucionalismo y umbral democrático en Chile: Hacia una nueva teoría constitucional", en Ius et Praxis, año 13, $\mathrm{N}^{\circ} 1$, pp. 68-69.

46 Carlos Carmona, 2001, "Un nuevo estadio en la relación Ley- Reglamento: el ámbito del reglamento", en Revista de Derecho Público, Nº3, pp. 154-155. 
Kamel Cazor Aliste

Emilio Pfeffer Urquiaga

más expedita ejecución de la ley; consecuentemente con ello el reglamento no sustituye a la ley sino que colabora con ella, complementa lo que ésta ha dejado de forma deliberada solo esbozado o lo que ha iniciado, ha dejado sin terminar. Claramente la ley no puede renunciar a regular los aspectos que la Constitución le manda normar, por eso no son del todo válidas las cláusulas de remisión en blanco o incompletas; el decreto no puede ir más allá del complemento indispensable de la ley, no puede incluir más que lo que sea estrictamente indispensable para garantizar el desarrollo y ejecución de la ley. ${ }^{48}$

La teoría de la razonabilidad técnica, a su vez, ha sido desarrollada por nuestro Tribunal Constitucional ( $R o l N^{\circ}$ 253/1997), quien ha indicado que mediante el ejercicio de la potestad reglamentaria se dictan normas tendientes a la ejecución de un precepto legal y con estricta sujeción a éste, ayudando a que la ley pueda producir efectos jurídicos; expresado en otros términos, la ley hace una remisión al reglamento de ejecución para que complemente, bajo ciertas directrices, su contenido básico. ${ }^{49}$ En este contexto, en primer lugar, ha agregado el Tribunal Constitucional que cuando la relación ley-reglamento (dominio legal y potestad reglamentaria) constituyen un «todo jurídicamente armónico», es decir, si existe una estricta fidelidad entre ambos, necesariamente un pronunciamiento en esta situación sobre la constitucionalidad de un acto administrativo, conllevaría emitir un pronunciamiento sobre la constitucionalidad de una ley. Al contrario, y como segundo asunto, en el evento de que el reglamento se aparte de la ley habilitante, se produce la desvinculación entre ambos, ya que dejan de constituir un «todo jurídicamente armónico», para transformarse en partes de una relación ley-decreto reglamentario que se contrastan y repudian. En este caso, el reglamento sí puede ser objetado ante el Tribunal Constitucional, ya que dejaría de ser una intromisión en un acto legislativo. Toda esta interpretación se efectúa, por último, en orden a que el Tribunal Constitucional no está facultado para pronunciarse sobre la legalidad de los decretos supremos, sino solo sobre su constitucionalidad. Por ello, en virtud del argumento de la «razonabilidad técnica», se permite efectuar un examen de juridicidad mucho más de fondo, donde la desvinculación entre la ley y el reglamento, no es sólo producto de una mera verificación de legalidad -en la adecuación formal del decreto reglamentario a la ley habilitante-, sino que va más allá, e implica una revisión de constitucionalidad («el marco de posibilidades regulatorias que brinda la Constitución», utilizando las palabras del Tribunal Constitucional). ${ }^{50}$

Por último, la teoría de la intensidad de la reserva sostiene que ésta no posee la misma potencia en la forma que se plasma en el sistema constitucional. ${ }^{51}$ Por ejemplo, como ya se ha

\footnotetext{
48 Carmona, "Un nuevo", cit. nota n. 46, p. 185.

49 Carmona, "Un nuevo", cit. nota n. 46, p. 186.

50 Kamel Cazor, 2002, La sumisión a Derecho de los actos y disposiciones del Presidente de la República, Tomo II, Santiago, Universidad Central de Chile, pp. 144-145.

51 García, La reserva, cit. nota n. 37, pp. 217-250
} 
La búsqueda de criterios orientadores en la configuración de las potestades normativas en Chile.

adelantado, a propósito de los derechos fundamentales la reserva posee una particular intensidad; en cambio, tratándose de la parte orgánica, la reserva debe ser calificada de menos absoluta. ${ }^{52}$ Hay que considerar también que en virtud de la pluralidad de manifestaciones literales de la técnica de la reserva legal en el texto constitucional, se ha planteado la clasificación entre reserva absoluta y relativa. Algunos autores en el Derecho comparado, como Luís Villacorta, plantean la tesis del rechazo a tal distinción tradicional de la reserva, ya que se trataría de un distingo "meramente descriptivo, carente de relieve científico importante y no hace sino violentar la esencia de la propia institución tal como constitucionalmente ha sido configurada y lo que es más grave, acarrea consecuencias prácticas difíciles de predecir"; 53 e incluso, como indica este mismo autor, "la neta diferencia entre principio de legalidad y de reserva de ley se difumina con la interposición entre ambas instituciones de la reserva relativa, cuya diferencia respecto del principio de legalidad será meramente cuantitativa". ${ }^{4}$ Cuestión que, como se está viendo, hay que vincularla con la intensidad de la reserva misma, frente a la cual, se ha dicho, más que una distinción -entre reserva absoluta y reserva relativa- se está en presencia de un problema de interpretación jurídica, en donde no es posible construir una clasificación de reserva, sino sólo admitir una posibilidad de ésta, ya que se trata de perspectivas difíciles de conciliar. ${ }^{55}$

En esta perspectiva temática, hay quienes rechazan la idea de que a través de una "reserva legal absoluta" se intente cerrar el debate en torno a un concepto definitivo de reserva legal, ya que "lo válido es admitir modalidades y distinciones de la reserva de ley" ${ }^{56}$ (sobre todo teniendo en cuenta la heterogeneidad de reservas legales, la multiplicidad de combinaciones que pueden plasmarse y la consecuente flexibilización de las mismas). Al contrario, otros plantean una idea necesariamente rígida y sustantiva de la reserva, los cuales asimilan cualquier criterio de distinción de la misma a un "proceso de relativización", enfatizando "que la reserva de ley es mucho más que un criterio técnico-constitucional: es una garantía sustantiva para la vigencia de los derechos fundamentales". ${ }^{7}$

Si bien es cierto que dentro del sistema constitucional chileno, la más cercana relación entre el legislador democrático y los derechos fundamentales, lo constituye el rol de garantía

\footnotetext{
52 Carmona, "Un nuevo", cit. nota n. 46, pp. 187-188.

53 Carmona, "Un nuevo", cit. nota n. 46, p. 46.

54 Carmona, "Un nuevo", cit. nota n. 46 , p. 46

55 García, La reserva, cit. nota n. 37, p. 131. De la misma forma, citando a Ignacio De Otto, un problema no precisamente desdeñable en el supuesto de admitirse las reservas relativas es el control de los reglamentos que no infringen la ley pero sí la Constitución, o en los supuestos en los que el Reglamento regule -caso de admitirse el independiente- en un supuesto de reserva relativa sin que se haya producido previamente ley alguna (1989, Estudios sobre el Poder Judicial, Civitas, Madrid, p. 73).

$56 \quad$ García, La reserva, cit. nota n. 37, p. 129.

57 Arturo Fermandois, 2001, "La reserva legal: una garantía sustantiva que desaparece", en Revista Chilena de Derecho, V. $18, \mathrm{~N}^{\circ} 2$, pp. $288-291$.
} 
Kamel Cazor Aliste

Emilio Pfeffer Urquiaga

normativa que cumple en esta esfera la reserva legal. ${ }^{58}$ Para explicar esta vinculación, hay que partir del hecho que nuestro ordenamiento constitucional reconoce diversas clases de reserva de $l e y^{59}$, que pueden clasificarse de conformidad a variados criterios.

En la doctrina nacional, Gonzalo García plantea la clasificación entre reservas legales complementarias, limitativas, regulatorias y negativas. ${ }^{60}$ A partir de ello, según Carlos Carmona, "el ámbito del reglamento se determina partiendo de qué espacio entrega la Constitución a la ley en la regulación”, "entre más fuerte o absoluta sea la reserva, el dominio del legislador es más intenso y la intervención de la administración más débil", y -para este autor- "el reglamento interviene en mayor medida en las reservas legales regulatorias". ${ }^{61}$ En resumidas cuentas, citando nuevamente al profesor Carmona, "la existencia de reserva de ley respecto a una materia supone, pues, que ésta, al tener que ser abordada por el legislador, queda sustraída a la normación reglamentaria, pero no evita que las disposiciones del Ejecutivo puedan colaborar con ésta para complementar o particularizar, en aspectos instrumentales y con la debida sujeción a la ordenación legal superior, la materia reservada". ${ }^{62}$

Para Teodoro Ribera, en cambio, "el ámbito a regular está determinado en cada caso por el constituyente, al utilizar expresiones diversas para encomendar al legislador dicha tarea", teniendo la ley y el reglamento ámbitos y niveles de competencia distintos, tanto en cuanto a las materias que les corresponde regular, o en lo relativo a la intensidad de la regulación que el constituyente ha definido en cada caso; así, distingue entre la extensión de las materias posibles

58 Desde esta perspectiva, no hay que olvidar que la expresión "garantías de los derechos fundamentales", como indica Luís María Díez-Picazo, carece de un significado técnico-jurídico preciso. Hace referencia al conjunto de medios que el ordenamiento prevé para la protección, tutela o salvaguardia de los derechos fundamentales. Se trata de un conjunto heterogéneo, pues abarca tanto procedimientos de distinta índole como requisitos sustantivos, cuyo rasgo común es precisamente estar dirigidos a asegurar la observancia y la efectividad de los derechos fundamentales. Sin embargo, la citada expresión puede inducir a confusión, dada su proximidad lingüística con los términos "garantía institucional" y "garantía del contenido esencial"; términos que, en cambio, sí poseen un significado técnico-jurídico preciso (2005, Sistema de derechos fundamentales, Madrid, Civitas, p. 74).

59 En este punto cabe recordar, asimismo, que el examen de las garantías de los derechos fundamentales debe partir de un presupuesto básico: en el ordenamiento chileno, como bien es sabido, "el ejercicio de la soberanía reconoce como limitación el respeto de los derechos esenciales que emanan de la naturaleza humana", además, "es deber de los órganos del Estado respetar y promover tales derechos, garantizados por esta Constitución, así como por los tratados internacionales" (art. $5^{\circ}$, inc. $2^{\circ}$ ); asimismo, los derechos fundamentales vinculan a todos los poderes públicos, ya que "los preceptos de esta Constitución obligan tanto a los titulares o integrantes de dichos órganos como a toda persona, institución o grupo" (art. $6^{\circ}$, inc. $2^{\circ}$ ). Dicho en otras palabras, además de vincular-directa o indirectamente- a los particulares, los derechos fundamentales vinculan a todas las autoridades públicas que la Constitución establece, imponiéndose incluso al legislador democrático; no sólo, como ya se ha adelantado, en la perspectiva de su competencia atributiva (que no puede ser invadida por otro poder, ni abdicarse), sino también en el trascendente cometido del desarrollo y regulación de tales derechos subjetivos fundamentales. García, La reserva, cit. nota n. 37, p. 172.

Carmona, "Un nuevo", cit. nota n. 46, p. 190.

Carmona, "Un nuevo", cit. nota n. 46, p. 184. 
La búsqueda de criterios orientadores en la configuración de las potestades normativas en Chile.

de regular y la intensidad de dicha normativa: "La extensión o ámbitos de las materias posibles a regular -señala- es en el artículo 60 [63] meramente enumerativa, constituyendo en sí un campo legal mínimo y no máximo, dada la vigencia del mencionado numeral 20 (...) Sin embargo - prosigue-, en lo que respecta a la intensidad de la regulación, cabe distinguir entre los mandatos precisos que la Constitución contempla a favor del legislador mediante disposiciones expresas en cada caso, con la atribución genérica que lo autoriza a normar nuevas materias no consignadas en los numerales 1 a 19 del artículo 60 [63], en los términos exigidos en el numeral 20 ya citado". ${ }^{3}$ En esta última situación, para este autor, "en los casos no previstos expresamente en la Constitución, cabe aplicar el numeral 20 del artículo 60 [63], esto es, una limitación en los relativo a la intensidad o profundidad de la regulación, más no en cuanto al contenido que puede alcanzar". ${ }^{64}$

Para nosotros, por otra parte, de acuerdo al grado de especificidad con que la Constitución recoge la reserva, esta puede ser especial o general (por ejemplo, en materia de derechos fundamentales es posible constatar una reserva general derivada del art. $63, \mathrm{~N}^{\circ} 2$ y 20 , y art. $\left.19, N^{\circ} 26\right)$. En segundo lugar, de conformidad al nivel de especificidad material con que la Carta recepta la reserva, puede vislumbrarse una reserva material y otra formal (esta última, por vía del art. $63, \mathrm{~N}^{\circ} 20$, que establece las denominadas leyes de bases generales; sin olvidar tampoco la especificidad material de las leyes orgánicas y de quórum calificado). Finalmente, se hace referencia, más bien, a la rigidez de la reserva en relación con el reglamento, en virtud de ello cabe distinguir entre una reserva absoluta y otra relativa (asunto que -como ya se ha mencionado y teniendo en cuenta las observaciones formuladas sobre el particular- tiene especial incidencia en los derechos fundamentales).

De lo dicho hasta ahora, es posible colegir que la verdadera trascendencia se centra en la intensidad (densidad normativa) de la reserva legal, lo cual debe ser entendido dentro de la heterogeneidad de manifestaciones que posibilita nuestro sistema constitucional. De este modo, a nuestro parecer resultaría, en principio, coherente hablar de un correlato lógico en la regulación de los derechos fundamentales, entre una reserva general, absoluta y material. Sin embargo, no resulta del todo claro lo concerniente a la reserva formal del art. $63, \mathrm{~N}^{\circ} 20$, que posibilita que las leyes de bases generales regulen materias de garantías fundamentales (cuyo contenido esencial mínimo se encuentra reconocido en la Constitución), no obstante que su ordenación no se halla garantizada dentro del ámbito de reserva general (como acontece vía art. $63, \mathrm{~N}^{\circ} 2$ ). Situación que es posible constatarla, por ejemplo, en la ley No 19.638/1999, sobre "Constitución jurídica de las iglesias y organizaciones religiosas", que regula las denominadas "entidades religiosas", cuyo reconocimiento se sustenta en la garantía de la libertad de conciencia creencia

\footnotetext{
63 Teodoro Ribera, 2001, "Reserva legal, potestad reglamentaria y Constitución de 1980", en Revista de Derecho Público, Vol. 63, T. I, p. 481.

64

Ribera, "Reserva", cit. nota n. 63, p. 482.
} 
Kamel Cazor Aliste

Emilio Pfeffer Urquiaga

y culto del art. 19, $\mathrm{N}^{\circ} 6$. Tampoco hay que olvidar que, en esta esfera de reserva formal, puede desplegar su fuerza normativa la potestad reglamentaria autónoma, ya que es posible ejercerla en todas aquellas materias que no sean propias del dominio legal; y ubica ésta su similitud con la ley, toda vez que se trata de una potestad normativa que halla su fundamento directamente en la Constitución.

En el ámbito de la potestad reglamentaria de ejecución, el objetivo de la reserva legal no es sustraer ciertas materias a dicha potestad normativa, ya que el ejercicio de ésta siempre requiere, por regla general, de un previo apoderamiento legal; de ahí que con la reserva se trata de imponer al legislador el deber de regular con la densidad necesaria determinadas materias, estando prohibido remitirse al reglamento cualquier parte que haga referencia al contenido esencial de los derechos y libertades garantizados en el Texto fundamental (distinguiéndose entre el núcleo esencial y el complemento indispensable). Sin embargo, en el caso de la reserva formal, el reglamento autónomo puede apoderarse en la regulación de materias que no están expresamente reservadas al legislador (como acontece en los mandatos específicos que se expanden vía art. $63, \mathrm{~N}^{\circ} 2$ ), en donde se incluyen temáticas de derechos fundamentales. Lo que resulta claro, es sí en caso de que exista un previo apoderamiento legal de tales materias (derechos fundamentales), no cabe el ejercicio de la potestad reglamentaria independiente (principalmente en base al principio de jerarquía, que le da preeminencia a la ley). Al contrario, se debe esclarecer la situación de que no exista tal apoderamiento legal y se imponga la regulación reglamentaria autónoma, ¿sería posible esta última situación, tratándose de una temática de derechos fundamentales, sobre todo si el ámbito mínimo de regulación no está constitucionalmente delimitado?

Esta duda obliga a precisar dos cuestiones. Por una parte, cuál sería el ámbito de regulación de un reglamento autónomo en materia de derechos fundamentales, cuestión que podría producirse a través de la habilitación directa que la Constitución le da a esta potestad normativa, sobre todo si estamos en una esfera que no sería propia del ámbito material específico de la ley. No obstante ello y teniendo en cuenta la perspectiva constitucional, habría que, necesariamente, derivar la imposibilidad de regulación de los reglamentos independientes en esta materia, la que inexorablemente requiere un previo apoderamiento legal, excluyendo, por ende, la potestad reglamentaria autónoma. Es decir, si nos situamos dentro del paradigma liberal, se estaría dentro de lo que la doctrina ha denominado como "reserva legal de intervención", que se basa en el valor y efectos directos de la propiedad y libertad, excluyendo el poder reglamentario de la Administración en este ámbito; ${ }^{65}$ en cambio desde la perspectiva del paradigma social, la intervención legal juega un rol de garantía del pluralismo político, cuestión, esta última, que no asegura la potestad reglamentaria pese a su legitimidad democrática. Dicho en otros términos, 
La búsqueda de criterios orientadores en la configuración de las potestades normativas en Chile.

los derechos fundamentales son materias propias del dominio legal ( $\operatorname{art} .32, \mathrm{~N}^{\circ}$ ), esto es, se trata de materias que están reservadas a la ley por mandato -específico o general- del artículo 63, esfera que está vedada a la potestad reglamentaria autónoma del Presidente de la República (art. 93, $\mathrm{N}^{\circ} 16$ ); por lo tanto, de un modo general, igualmente les es aplicable lo dispuesto en el art. 19, $\mathrm{N}^{\circ} 26$, de la Carta.

Por otra parte, como no sería posible la regulación reglamentaria independiente, se debe necesariamente deducir que el alcance de esta reserva legal (formal-material) obliga a preservar el contenido esencial del derecho fundamental, toda vez que habría una especie de "reserva forzosa", que exige a la ley salvaguardar las determinaciones esenciales del núcleo intangible de los derechos y libertades, pues se trata de una temática que incide directamente en la esfera jurídica de los ciudadanos (por cuanto concierne a la libertad y la propiedad, o más modernamente expresada como libre desarrollo de la persona); teniendo en cuenta, además, las cláusulas generales de dignidad humana y libre desarrollo de la personalidad que se derivan del art. $1^{\circ}$ de la Constitución. En la doctrina nacional hay opiniones aparentemente contrarias a esta conclusión, como es el caso de Eduardo Aldunate, que ha indicado "que nuestro sistema constitucional no contempla una reserva legal genérica en materia de regulación de derechos fundamentales (...) en el artículo 63 -señala- no se encuentra una referencia genérica a la regulación de derechos fundamentales". ${ }^{66}$ Sin embargo, su inferencia no queda del todo clarificada, cuando además plantea que la reserva legal en nuestra Constitución es "simplemente un ámbito excluyente de la potestad reglamentaria autónoma en todos aquellos casos en que un precepto iusfundamental encomiende su regulación a la ley, y en todo lo que se refiera a establecer las bases esenciales del ordenamiento jurídico de los derechos fundamentales según el artículo $63 \mathrm{~N}^{\circ} 20$ (sea cual sea la interpretación que a esta expresión se pueda dar)" ${ }^{67}$ Con lo cual reconocería, como un ámbito excluyente de la potestad reglamentaria independiente, una reserva formal y general en la regulación de los derechos constitucionales, por vía de las leyes de bases esenciales.

De lo dicho podríamos concluir que, además de la reserva general y material, ya mencionada, en la regulación de los derechos fundamentales, habría que agregar, como materias propias del dominio legal, lo concerniente a los derechos subjetivos fundamentales que pueden ser regulados por leyes de bases esenciales. Plasmándose, de esta forma, una reserva general, forzosa y horizontal (ámbito), la cual inexorablemente debería cubrir, como reserva vertical (intensidad), la densidad normativa necesaria en torno al núcleo intangible del derecho regulado; en donde también hay que considerar aquellos derechos expresamente sometidos a una reserva, y aquellos que no lo están. Sin embargo, como se ha puesto de relieve, dada la heterogeneidad 
Kamel Cazor Aliste

Emilio Pfeffer Urquiaga

de reservas legales y las múltiples combinaciones que pueden plasmarse entre ellas, no es sostenible ni operativo en nuestro ordenamiento constitucional, plantear una tesis basada en una idea rígida de la reserva, ya que no siempre la pérdida de intensidad o flexibilización de las leyes puede verse como un fenómeno contrario a las exigencias y rol de la reserva legal, es decir, flexibilizar no necesariamente es relativizar o debilitar la reserva, ya que en la relación ley-reglamento, este último debe regular todo lo indispensable para garantizar la aplicación de la ley. En este contexto, claramente la intensidad de la reserva se modula en función de la materia, y a mayor grado de afectación de un derecho fundamental, menos flexible serán las posibilidades de remisión de la ley al reglamento; en los demás casos de reserva, el ejercicio de la potestad reglamentaria reconoce un cierto margen para introducir opciones políticas, pues la Administración, como poder legitimado democráticamente y con un claro reconocimiento constitucional de su potestad reglamentaria, no pondría necesariamente en entredicho con su ejercicio normativo la función de garantía de la reserva legal, ni tampoco transgrediría el pluralismo democrático.

\section{II.3. Tercer criterio orientador: "Perspectivas del control jurídico en la relación ley- reglamento, a propósito de la verificación de las actuaciones administrativas" ${ }^{68}$}

El límite intrínseco de todo control -en particular, del control jurídico- se traduce en la existencia de un parámetro jurídico en el cual verificar, por ejemplo, una determinada actuación administrativa, y en la determinación de este límite intrínseco, juega un importante papel la labor del legislador. En efecto, como expresa Mariano Bacigalupo, éste no puede habilitar al órgano de control a verificar una determinada actuación u omisión, si al mismo tiempo no le aporta parámetros jurídicos que hagan viable el control pretendido, es decir, si no programa dicha actuación con la densidad normativa necesaria. La cuestión estriba entonces -prosigue este autor- en saber cuándo el ordenamiento jurídico aporta un parámetro discernible para la adopción de una decisión administrativa y cuándo no, es decir, un parámetro discernible que permita controlar la conformidad a Derecho de una decisión administrativa que aplica, o inaplica, un concepto normativo. ${ }^{69}$

De este modo y siguiendo el ejemplo de la actuación administrativa, se debe vislumbrar,

Las ideas matrices de este apartado también es posible encontrarlas en: Cazor, La sumisión, cit. nota n. 50, pp. 33-41.

69 Mariano Bacigalupo, 1997, La discrecionalidad administrativa, Madrid, Marcial Pons, pp. 69 y 70 . Así, por ejemplo, en lo relativo al margen de discrecionalidad de los conceptos normativos indeterminados, Tomás Ramón Fernández señala: "El propio margen creado por la Ley habilitante del poder discrecional hace que todas las soluciones susceptibles de ser imaginadas dentro de él sean, en principio, indiferentes. Pero ¡cuidado...!, legalmente indiferente, no indiferentes jurídicamente, que es cosa muy distinta, como la fórmula dual «Ley y Derecho» subraya expresivamente" (1993, «De nuevo sobre el poder discrecional y su ejercicio arbitrario», en Revista Española de Derecho Administrativo, $\mathrm{N}^{\circ} 80$, octubre-diciembre, p. 584). 
La búsqueda de criterios orientadores en la configuración de las potestades normativas en Chile.

como punto de partida, la estructura de las normas que otorgan la atribución o potestad a la Administración, y luego, los límites intrínsecos del control jurídico que se deriven de aquélla. En otras palabras, según sea la densidad de la programación legal de la actividad administrativa constitucionalmente exigida, como cuestión previa, servirá para determinar, a su vez, los límites intrínsecos del control jurídico. ${ }^{70}$

El criterio que se ha expuesto resulta perfectamente coherente y aplicable con el sistema constitucional chileno. En efecto, la relación de la intensidad del control jurídico de la actuación administrativa respecto de la densidad de su programación jurídica, se traduce en que es el legislador quien tiene en sus manos graduar la intensidad del control jurisdiccional de la acción administrativa, según la programe con mayor o menor densidad normativa. Por ello, el estudio de los principios constitucionales, de los que depende que el legislador programe la actuación administrativa con la densidad normativa necesaria para que los jueces puedan fiscalizarla con la intensidad que consideren constitucionalmente exigida, ponen de relieve los dos principios, ya mencionados, que coexisten en nuestro ordenamiento constitucional: el principio de juridicidad y, sobre todo, el principio de reserva de ley.

En lo que toca al ámbito de interrelación entre el principio de reserva de ley y la intensidad del control judicial de la Administración, el sistema chileno se encuentra muy cercano a lo que manifiesta en la actualidad la doctrina alemana. En efecto, sobre el particular, la doctrina germana establece que la indeterminación legislativa significa el desplazamiento del poder decisorio al Ejecutivo, unido, de ese modo, a una reducción de la tutela judicial. ${ }^{11}$ Por esta razón, "las normas de conducta dirigidas [por el legislador o el constituyente] a la Administración, son siempre a la vez normas de control, dirigidas al juez contencioso-administrativo [o constitucional] (...) De este modo, sería la densidad con la que el ordenamiento jurídico programa la acción administrativa la que, al mismo tiempo, determinaría la intensidad de su control jurídico"72.

Respecto al tema en cuestión, se debe igualmente recordar lo que ya se dijo en torno a las consecuencias del principio de legalidad como principio de juridicidad. El que, a su vez, encuentra su regulación en la técnica de reserva de ley, como parte o especie del género de la juridicidad. Sobre el particular, y haciendo una vinculación extensiva con el tema del control

Por ello, como bien dice Joaquín Tornos Mas, "el núcleo de la polémica no debe centrarse (...) en cuál sea la posición constitucional del poder judicial y de la Administración, para resolver en base a este criterio la relación entre los dos poderes (...) La atención debe centrarse en la defensa de la esencia del control de legalidad de la actuación administrativa, de modo que se amplíe hasta el máximo su extensión sin llegar a desnaturalizarlo" (1996, «Discrecionalidad e intervención administrativa económica», en AAVV, Discrecionalidad administrativa y control judicial. I. Jornadas de Estudio del Gabinete Jurídico de la Junta de Andalucía, Madrid, Civitas, p. 392). Así lo sostiene, entre otros, Fritz Ossenbühl, citado por Bacigalupo, La discrecionalidad, cit. nota n. 69, p. 81. Bacigalupo, La discrecionalidad, cit. nota n. 69, p. 82. Lo intercalado es nuestro. 
Kamel Cazor Aliste

Emilio Pfeffer Urquiaga

jurídico, cabe destacarse en la primera situación (de sujeción integral con la generalidad de la juridicidad), un parámetro de programación indeterminado, donde la Administración se vincula con la generalidad del ordenamiento y el control se traduce en un ajuste del acto o norma a dicho ordenamiento. En la segunda situación (de sujeción con una parte o especie de la juridicidad), a su vez, el parámetro de densidad normativa con que se vincula la Administración, ya no es con la generalidad de la juridicidad sino con una parte o especie de ella, cuya programación se encuentra reservada privativamente a la ley, lo que posibilita en mejor medida el control jurídico, por cuanto la actuación administrativa está sometida específicamente a la ley que la programa con la densidad normativa pertinente.

Como consecuencia de lo anterior, se puede expresar que, en el primer caso, se está hablando del carácter negativo de la programación normativa; y, en el segundo, del carácter positivo de dicha programación.

El carácter positivo o negativo de la programación normativa de la acción administrativa, se relaciona con la posibilidad de ser sometida a control jurídico. Así, de este modo, como algo se ha adelantado, cuando la programación es positiva se posibilita en gran medida la viabilidad del control jurídico.

La situación es más compleja cuando hay ausencia de programación positiva, es decir, cuando se está frente a un caso de programación negativa. En este lance, no significa que la acción administrativa se lleve a cabo sin sujeción alguna a reglas jurídicas y, por lo tanto, sin posibilidad alguna de ser sometida a un control jurídico. Así, por ejemplo, como ocurre en el ordenamiento chileno, la actuación administrativa no sólo está sometida a la ley, sino también a la Constitución y al Derecho (arts. $6^{\circ}$ y $7^{\circ}$ ); en consecuencia, cabe siempre, al menos, el control de su juridicidad y, en particular, su conformidad con los principios generales del Derecho $^{73}$.

De esta forma, cuando se plantea el caso de una programación negativa, tanto los derechos

Por esta razón, en esta situación, Antonio Pérez Luño parte del supuesto que los principios generales del Derecho actúan como metanormas, es decir, como reglas orientadoras para el conocimiento, para la interpretación y para la aplicación de las restantes normas jurídicas. Asimismo, resalta su idoneidad para servir de parámetro de valoración que posibilita el control jurisdiccional de las actuaciones administrativas. Además, para este autor, en un sentido ontológico, -los principios generales del derecho- son elementos o partes integrantes del ordenamiento. Así de este modo, y partiendo de dichas consideraciones, incluye en su tesis a los principios generales del derecho como una manifestación evidente de la mitología jurídica. No obstante concluye señalando: "Los principios generales del derecho son un mito jurídico, pero un mito que responde a una necesidad propia de los ordenamientos jurídicos de los Estados de derecho: reconocer el valor de la seguridad jurídica" (1997, «Los principios generales del derecho: ¿Un mito jurídico?», en Revista de Estudios Políticos (Nueva Época), Núm. 98. Octubre-Diciembre, pp. 16-23). 
La búsqueda de criterios orientadores en la configuración de las potestades normativas en Chile.

y principios constitucionales como los principios generales del Derecho sólo vinculan negativamente las decisiones administrativas. Es decir, como señala Mariano Bacigalupo, "se limitan a excluir aquellas soluciones que desconozcan los valores jurídicos en ellos consagrados, pero no indican positivamente cuál es la que se ha de adoptar entre aquellas otras que no adolezcan de tal vicio. A ello se añade -prosigue Bacigalupo- que tanto los principios constitucionales que rigen la actuación de los poderes públicos como los principios generales del Derecho se construyen, a su vez, sobre la base de conceptos jurídicos indeterminados (arbitrariedad, racionalidad, razonabilidad, proporcionalidad, buena fe, confianza legítima, etc.) que (...) sólo en sus zonas de certeza positiva y negativa -pero no así en sus respectivas zonas de incertidumbre- permiten un juicio seguro sobre su infracción (manifiesta) o no"74.

Dentro de este contexto de programación negativa, también se ha expresado, que, en caso de impugnación, el juez realiza un control que ya no va a articularse en torno a las tradicionales nociones de legalidad y oportunidad, sino que va a ser un control genérico de ajuste del acto al ordenamiento, al «marco programático de acción» ${ }^{75}$. Esta situación parece clara, cuando el Tribunal Constitucional chileno invoca en su doctrina la interpretación conforme a la Constitución del respectivo decreto supremo. Así ha acontecido, por ejemplo, en el fallo rol $\mathrm{N}^{\circ}$ 465 , de 2006, que rechaza el requerimiento de inconstitucionalidad deducido contra el decreto supremo $\mathrm{N}^{\circ} 181$, de 2005, donde se indica que, "esta Magistratura seguirá, una vez más, el principio de buscar la interpretación de las normas que permitan resolver, dentro de lo posible, su conformidad con la Constitución, declarando la inconstitucionalidad de rigor únicamente cuando, más allá de toda duda razonable, no es posible armonizarla con la Constitución" $\left(\text { Considerando } 52^{\circ}\right)^{76}$.

Bacigalupo, La discrecionalidad, cit. nota n. 69, p. 85.

Miguel Beltrán de Felipe, 1995, Discrecionalidad administrativa y Constitución, Madrid, Tecnos, pp. 205-207.

Esta circunstancia, no obstante, en ningún caso puede traducirse, como veremos más adelante, cuando el ordenamiento jurídico abre un abanico de soluciones permitidas, en que los jueces y tribunales, por la vía del control, la sustituyan por «su» decisión más óptima, razonada, adecuada, etc. Ratifica esta última aseveración, la anteriormente mencionada sentencia rol $\mathrm{N}^{\circ} 465$, que, debido a su importancia, reproduzco textualmente los Considerando pertinentes: "Cuarto: (...) Respecto de la presunta infracción de los artículos $7^{\circ}$ y $19 N^{\circ}$ s 11 y 21 de la Ley Fundamental, indican [los requirentes] cómo una o más de dichas normas constitucionales habría sido quebrantada por alguna de las disposiciones reglamentarias cuestionadas. Sin embargo, no consignan fundamentación destinada a demostrar específica y determinadamente cómo una o más de las normas objetadas infringirían las demás disposiciones constitucionales cuya trasgresión se denuncia, lo que impediría provocar un pronunciamiento jurisdiccional respecto de ellas. De esta forma, el análisis del requerimiento se ceñirá a aquellas objeciones respecto de las cuales se precisa y fundamenta el vicio de constitucionalidad que se imputa (...) Vigésimo segundo: Que, como una cuestión previa a la resolución de las infracciones planteadas en este capítulo, el Tribunal debe recordar lo que ha sido su jurisprudencia constante [causa rol $\mathrm{N}^{\circ} 325$, Considerando $38^{\circ}$ ] en cuanto a ceñirse estrictamente al examen jurídico del asunto sometido a su decisión, excluyendo cualquier consideración de mérito, oportunidad o conveniencia, por lo que se omitirá cualquier pronunciamiento sobre las objeciones sobre esa naturaleza que el requerimiento formula al fundamentar el presente capítulo de inconstitucionalidad". 
Kamel Cazor Aliste

Emilio Pfeffer Urquiaga

Resumiendo todo lo expresado, se puede señalar que el carácter positivo del control judicial de la actividad administrativa no depende de la mayor o menor predisposición de los jueces, sino única y exclusivamente de que el legislador programe con la densidad normativa necesaria el contenido de las decisiones administrativas; es decir, de que el legislador ponga a disposición de aquéllos parámetros de control dotados de una estructura lógico-normativa que haga viable el pleno control jurídico-sustantivo de la actividad fiscalizada. ${ }^{77} \mathrm{Y}$ es que, como recuerda Joaquín Tornos Mas, "la estructura condiciona el proceso de razonamiento en la interpretación de la norma y, por tanto, el grado de intervención judicial en la revisión de la actuación administrativa". ${ }^{78}$ Todo lo cual, en última instancia, designa la amplitud del espectro de intensidad del control judicial. ${ }^{79}$ En donde dicho control puede oscilar, dependiendo de la densidad normativa con la que el ordenamiento jurídico programe la actividad administrativa en cada caso, entre un control puramente negativo, si la densidad de programación positiva es nula o insignificante, y un control perfectamente positivo, si la densidad de programación positiva es elevada.

El enfoque que se ha descrito hasta ahora, permite diferenciar, a su vez, los dos grandes objetos del control jurídico: el control del ejercicio de las potestades administrativas y el control de su atribución.

En el caso del control del ejercicio de las potestades administrativas, su alcance se rige por los llamados límites intrínsecos del control jurídico, que se traducen en la existencia de un parámetro jurídico en el cual verificar una determinada actuación administrativa. Y en el caso del control de la atribución, se hace mención a los límites con que la Constitución sujeta la atribución de las respectivas potestades ${ }^{80}$. Asunto de mucha relevancia, toda vez que el control que lleva a cabo el Tribunal Constitucional chileno de los decretos supremos, es más de atribución que de ejercicio.

Respecto al control de la atribución, cabe señalar que toda potestad administrativa tiene su origen en la atribución expresa que el ordenamiento jurídico le otorga. Al mismo tiempo ocurre que el alcance o intensidad de dicha atribución puede ser mayor o menor, según sea el margen con que se establezca. Así acontece, por ejemplo, con el margen de discrecionalidad que se le atribuye a una potestad administrativa, en cuyo caso el objeto del control jurídico será determinar el verdadero ámbito de discrecionalidad asignado por la normatividad a la potestad que se verifica.

\footnotetext{
77 Bacigalupo, La discrecionalidad, cit. nota n. 69, p. 92.

Tornos, «Discrecionalidad», cit. nota n. 70, p. 393.

Beltrán, Discrecionalidad, cit. nota n. 75, p. 38.

Bacigalupo, La discrecionalidad, cit. nota n. 69, p. 92.
} 
La búsqueda de criterios orientadores en la configuración de las potestades normativas en Chile.

Del mismo modo, la atribución de la potestad administrativa está condicionada por los valores y principios en que se fundamenta el ordenamiento jurídico dentro de un Estado constitucional. Por ejemplo, los postulados propios del Estado Social (como acontece en España, no así en Chile) se decantan a favor de la atribución de potestades discrecionales a la Administración, cuestión que se debe conjugar con un elemento esencial del Estado de Derecho, que exige el control judicial de aquellas potestades. Lo que plantea la dificultad de encontrar un equilibrio razonable entre la atribución de la potestad administrativa y su control jurídico. ${ }^{81}$

Sobre este asunto David Blanquer indica que "la atribución debe ser tal que confiera a la Administración un cierto margen de opción o elección (en principio la discrecionalidad no puede reducirse a cero), y al mismo tiempo suministre a los Tribunales parámetros jurídicos que permitan fiscalizar si se han respetado los límites de la discrecionalidad o estos han sido rebasados (el margen de discrecionalidad no puede ser tan amplio como para orillar esos parámetros, ya que sin ellos no puede haber control y se sientan las bases para consentir la sustitución judicial de la discrecionalidad administrativa)" ${ }^{22}$. Asimismo, el objeto del control no se limita a la atribución de la potestad administrativa sino también a la forma de su ejercicio -o no ejercicio-, que es igualmente susceptible de control jurídico. Donde este control del ejercicio se rige, fundamentalmente, por la existencia de un parámetro jurídico en el cual verificar el objeto de su fiscalización. ${ }^{83}$

La distinción entre control de la atribución y control del ejercicio, no es meramente teórica sino también de gran relevancia práctica. En efecto, su importancia salta a la vista, como ocurre en el sistema orgánico de control jurídico en Chile, cuando no es una misma jurisdicción la que compite en la fiscalización de la actuación administrativa. Así, por ejemplo, si la potestad discrecional está atribuida por ley, el juez ordinario no puede confundir el control de juridicidad de su ejercicio, que le compete a él, con el control de constitucionalidad de su atribución, pues correspondería este control, en tales casos, sobre todo a la jurisdicción que lleva a cabo el Tribunal Constitucional, con los alcances y limitaciones mencionados anteriormente.

En este sentido como indica Mariano Bacigalupo: “En particular, no está el juez ordinario legitimado para extralimitarse en el control del ejercicio de una potestad discrecional como única forma de corregir, en sede aplicativa, una atribución legal de discrecionalidad que él estima excesiva y aun inconstitucional (en tanto vulneradora, por ejemplo, de los principios constitucionales de reserva de ley y de la tutela judicial efectiva)" ${ }^{\prime 4}$. Al no poder el juez ordinario

David Blanquer, 1998, El control de los reglamentos arbitrarios, Madrid, Civitas, pp. 70-72. Blanquer, El control, cit. nota n. 81, p. 72.

Sobre el particular, cabe destacar el estudio realizado por David Blanquer, que diferencia tres escenarios en este ámbito de control: la inactividad en el ejercicio de la potestad, su ejercicio tardío o el ejercicio excesivamente frecuente (Blanquer, El control, cit. nota n. 81, pp. 81-102).

Bacigalupo, La discrecionalidad, cit. nota n. 69, p. 103. 
Kamel Cazor Aliste

Emilio Pfeffer Urquiaga

extralimitarse en el control del ejercicio como forma de corregir una atribución legal excesiva, puede llegar incluso esta situación a hacer imposible el control judicial y a lesionar el derecho a la tutela judicial efectiva. Por cuanto, en el caso que una ley atribuya un margen excesivo de discrecionalidad, se estaría frente a un vicio de inconstitucionalidad por insuficiencia de la ley de habilitación, ante el cual los Tribunales pueden plantear una cuestión de inconstitucionalidad, pero no pueden declarar la existencia de una atribución legal de excesiva discrecionalidad a la potestad administrativa. ${ }^{85}$ Por ejemplo, esta situación se encontraría en el caso que se efectuara una habilitación legal de discrecionalidad a la Administración, sobre materias reservadas a los derechos fundamentales y libertades públicas, donde la discrecionalidad de la actuación administrativa es casi inexistente. ${ }^{86}$

En fin, del mismo modo David Blanquer, haciendo referencia al control de la potestad reglamentaria como potestad discrecional, expresa que "corresponde a los Tribunales de lo Contencioso-Administrativo el control del ejercicio de la potestad reglamentaria, el control de atribución de esa potestad discrecional debe ser desarrollado por el Tribunal Constitucional" $" 87$.

\section{II.4. Cuarto criterio orientador: "Control jurídico abstracto y concreto en la competencia atributiva del Tribunal Constitucional, a propósito de la verificación de la relación ley-reglamento"}

Con frecuencia el Tribunal Constitucional ha tenido oportunidad de precisar la distinta naturaleza que exhibe el control abstracto y el control concreto de la constitucionalidad de preceptos legales. Una de las cuestiones esenciales, a nuestro parecer, a fin de precisar la perspectiva de verificación cuando está involucrada la temática de la relación ley-reglamento.

85 Bacigalupo, La discrecionalidad, cit. nota n. 69, pp. 181 y sig., y pp. 237 y sig.

86 Sobre el particular, resulta conveniente citar Dictamen del Consejo de Estado Español de 10 de abril de 1997 (expediente número 982/97, relativo al proyecto de Real Decreto por el que se aprueba el Reglamento General de Conductores): «En el marco constitucional de un Estado social y democrático de Derecho la regulación de los elementos esenciales de la libertad y la propiedad de los ciudadanos debe hacerse en sede parlamentaria, que es donde reside la representación de la soberanía nacional. En sede administrativa puede realizarse un desarrollo reglamentario de aquello que afecte a la organización administrativa o las cuestiones adjetivas o procedimentales de la intervención administrativa en actividades privadas de interés público. Pero en el Reglamento no puede suplirse la omisión o insuficiente regulación en sede parlamentaria de los elementos esenciales configuradores de la libertad y la propiedad de los ciudadanos. Para realizar el desarrollo reglamentario de materias reservadas a la Ley, no sólo es necesario que exista esa previa regulación en sede parlamentaria, sino que además la norma aprobada por las Cortes Generales debe tener un contenido mínimo, una densidad suficiente para que el Juez pueda controlar si el desarrollo reglamentario se ajusta al marco de la Ley o si lo excede (mensurabilidad), y que permita al ciudadano prever con un mínimo de seguridad cuál puede ser el desarrollo reglamentario (previsibilidad). En materias reservadas a la Ley, una habilitación genérica o difusa que establezca una deslegalización indeterminada es contraria a la Constitución» (citado en Blanquer, El control, cit. nota n. 81, p. 75). 
La búsqueda de criterios orientadores en la configuración de las potestades normativas en Chile.

En efecto, como bien es conocido, al conocer y fallar requerimientos de inaplicabilidad, ha puesto de relieve que solo procede declarar inaplicable las normas legales objetadas en el evento de que su aplicación en la gestión pendiente resulte contraria a la Constitución, en consideración a las particularidades del caso concreto respecto del cual debe ponderarse el efecto de conformidad o contrariedad que, con la Carta Fundamental produce la aplicación del precepto legal tachado en esa especifica gestión pendiente.

Tal competencia, naturalmente distinta a la que de oficio o en ejercicio de la acción pública de inconstitucionalidad puede estar también llamado, ha servido para enfatizar la diferencia de uno u otro tipo de control.

En éste último, al ejercer la acción de inconstitucionalidad el Tribunal ha razonado que debe cerciorarse que en todas las hipótesis posibles de aplicación la norma legal pugna con los valores, principios y reglas contenidas en la Carta Fundamental para declararla inconstitucional $y$, con ello generar el efecto de su derogación, aunque sin efectos retroactivos.

Lo dicho hasta ahora, se encuentra ratificado en la sentencia de inaplicabilidad (relativa a la regla solve et repete), rol $\mathrm{N}^{\circ} 946$, de $1^{\circ}$ de julio de 2008 , de la que reproducimos textualmente su considerando quinto:

"Que, antes de entrar a la resolución del asunto sublite, se recordará que, como lo ha señalado reiteradamente este Tribunal (roles $\mathrm{N}^{\circ} 478,546$, Capítulo I, 473, 517, 535, 588 y 589, entre otros), la naturaleza de la actual acción de inaplicabilidad tiene marcadas diferencias con la similar prevista en la Carta Fundamental con anterioridad a la reforma del año 2005, destacando especialmente la constatación de que de la simple comparación del texto de la norma actual con el antiguo artículo 80 de la Carta Fundamental, que entregaba esta facultad a la Corte Suprema, se desprende que mientras antes se trataba de una confrontación directa entre la norma legal y la disposición constitucional, ahora se está en presencia de una situación diferente, por cuanto lo que podrá ser declarado inconstitucional, por motivos de forma o de fondo, es la aplicación del precepto legal impugnado a un caso concreto, lo que relativiza el examen abstracto de constitucionalidad, marcando así una clara diferencia con la regulación prevista por el texto constitucional anterior.

Lo expresado hace ostensible que las características y circunstancias del caso concreto de que se trate, han adquirido en la actualidad una relevancia mayor de la que debía atribuírseles entes de 2005 pues, ahora, la decisión jurisdiccional de esta Magistratura ha de recaer en la conformidad o contrariedad con la Constitución que la aplicación del precepto impugnado pueda tener en cada caso concreto, lo que no implica, necesariamente, una contradicción abstracta y universal con la preceptiva constitucional".

Las características singulares del caso concreto - naturaleza de la gestión pendiente, acción 
Kamel Cazor Aliste

Emilio Pfeffer Urquiaga

ejercida, estado, efectos que en ella produciría la aplicación del precepto legal tachado, entre otros aspectos- han sido algunos de los criterios de análisis que ha guiado a la Magistratura Constitucional cuando le ha correspondido emitir pronunciamiento estimatorio o desestimatorio en sede de inaplicabilidad. Al contrario, en ejercicio de la acción de inconstitucionalidad, al no resolver en referencia a un caso concreto -que por lo demás no existe- tendrá que abstraerse totalmente del efecto singular que una eventual contrariedad con la Carta Fundamental pueda generar la aplicación del precepto legal, la que habrá de comprobarse sea universal.

Sobre las características del control concreto de constitucionalidad que se ejerce vía acción de inaplicabilidad, también se ha dicho que ésta "no impide que, en un mismo juicio de constitucionalidad, un precepto sea declarado constitucional en abstracto e inconstitucional en su aplicación concreta. En la sentencia rol núm. 707 -se agrega- la legitimación constitucional abstracta de una ley, juzgada en función de los fines perseguidos por el legislador, no es obstáculo para declarar, al mismo tiempo, su inaplicabilidad concreta por producir efectos contrarios a la Constitución en el caso sub lite" ${ }^{88}$

Si bien el Tribunal ha señalado -ahora desde la perspectiva del control de normas infralegales- que en ejercicio de la facultad de declarar la inconstitucionalidad de los decretos supremos debe proceder con prescindencia de la aplicación de las normas a casos concretos o particulares, ya que por su naturaleza en este caso se estaría frente a un control abstracto de constitucionalidad que tiene como límite los hechos, tal como se ha resuelto, entre otros en los roles $\mathrm{N}^{\mathrm{o}} \mathrm{s} 450$ y 465 . Criterio que ha sido flexibilizado por el Tribunal, a lo menos, en cuatro oportunidades, lo cual lleva a reflexionar sobre la validez de aplicar como criterio orientador para resolver el conflicto de constitucionalidad esta categoría conceptual que distingue entre control abstracto y control concreto.

El Tribunal ha razonado que no cabe excluir en el control de un precepto legal o reglamentario la consideración de los efectos que tales órdenes normativos puedan producir, en particular, en relación a los derechos fundamentales, ya que todo órgano del Estado está obligado a respetarlos y promoverlos. Ejemplos expresivos de ello son el proyecto de ley sobre trasplantes de órganos (rol $\mathrm{N}^{\mathrm{o}} 220$ ), donde luego de analizar los informes científicos acompañados el Tribunal llegó a la conclusión de que la abolición total e irreversible de todas las funciones encefálicas constituye la muerte real, definitiva, unívoca e inequívoca del ser humano. Luego, respecto del Decreto Supremo que introdujo la restricción a la circulación de los vehículos catalíticos (rol $\mathrm{N}^{\mathrm{0}} 325$ ), señaló que atendida la situación ambiental existente resulta necesaria para proteger la salud de la población. También en relación al Decreto Supremo

88 Manuel Núñez, 2008, "El control de la igualdad en la aplicación de la ley como factor de expansión del control concreto de constitucionalidad de las leyes", publicado en Arturo Fermandois (Ed.), Sentencias destacadas 2007. Una mirada desde la perspectiva de las políticas públicas, Santiago, Libertad y Desarrollo, pp. 123-161. 
La búsqueda de criterios orientadores en la configuración de las potestades normativas en Chile.

que estableció la norma de emisión para molibdeno y sulfatos de efluentes descargados desde tranques de relave al estero Carén (rol $\mathrm{N}^{\circ}$ 577), razonó para desestimarlo que no se había acreditado la existencia de una situación o riesgo que pusiera en peligro el derecho a la vida y a la integridad física y psíquica. Finalmente, en el caso de la denominada "píldora del día después" ponderó el efecto del fármaco y la evidencia científica, que estimó dudosa, para acoger el requerimiento y declarar inconstitucional el Decreto Supremo respectivo. Antes, en relación a esta misma materia, había aplicado el "principio de primacía de la realidad por sobre el nominalismo" para resolver que la norma impugnada (rol No 591) -una resolución ministerialtenía las características propias de un decreto supremo, por lo que al no haber sido aprobada con las formalidades propias de esa clase de acto administrativo era inconstitucional.

Si el control abstracto de constitucionalidad se reduce, exclusivamente, al contraste entre una norma infraconstitucional y aquélla de máxima jerarquía positiva, el Tribunal Constitucional se apartó de tal parámetro de control en los cuatro casos referidos, pues lejos de abstraerse de ponderar el contexto fáctico en el que la norma controlada se aplica y los efectos de esa aplicación, se avocó al examen de tales cuestiones justificándolo en la creciente complejidad de los problemas que actualmente deben abordar las jurisdicciones constitucionales, las que sostiene las llevan a apreciar con mayor énfasis ciertos hechos relacionados con la ciencia o con la técnica, y los efectos que el acto administrativo genera, a fin de asegurar con mayor eficacia la supremacía material y formal de la Constitución.

Con todo, la formulación de juicios de mérito representa un límite al que pronunciamientos de esa especie deben circunscribirse, para no olvidar que el control de constitucionalidad exhibe naturaleza jurídica, de modo tal que el Tribunal a cargo no invada el campo propio de los órganos legislativos, administrativos y jurisdiccionales, por lo que les debe estar vedado entrar a calificar el mérito, oportunidad o conveniencia de la norma impugnada y, en tal sentido, deberán limitar su pronunciamiento a la conformidad o disconformidad del acto de cuyo control se trate, con los principios, valores y normas constitucionales. En efecto, se debe recordar, igualmente, lo concerniente a la teoría del control, en el sentido de que éste siempre se traduce en la verificación de limitaciones preestablecidas, y nunca se convierte en una limitación en si misma, es decir, la decisión es producto de un juicio de conformidad con ciertas reglas cuyo resultado es secundario y una consecuencia del parámetro de juridicidad que es intrínseco a todo control jurídico. Excluyendo, por un lado, la absoluta libertad de valoración del órgano controlante, y, por la otra, que la decisión del Tribunal se traduzca, por la vía del control, en «su» decisión más óptima, razonada o adecuada, sustituyendo de esta forma el producto normativo del órgano controlado (ya sea el Legislador o la Administración).

En síntesis, el control de la constitucionalidad de los decretos supremos ha justificado, en la praxis del Tribunal Constitucional, que éste verifique su constitucionalidad en referencia a la situación concreta en que tal acto administrativo producirá sus efectos, lo que hasta ahora se ha considerado un parámetro válido de control. De ahí que el análisis en cuestión se debe 
Kamel Cazor Aliste

Emilio Pfeffer Urquiaga

centrar en el ámbito e intensidad de la competencia que asume el Tribunal Constitucional para resolver dichos asuntos. Contexto en el cual hay que hacer mención al verdadero rol de la jurisdicción constitucional en Chile en este tipo de verificación, ya que pone en evidencia los límites que la propia Constitución va a imponer al Tribunal, y es, precisamente, entre tales limitaciones en donde deberá llevar a cabo su justificación argumentativa ${ }^{89}$ ("constitucionalmente adecuada"), es decir, con elevados estándares de racionalidad argumentativa. Sin olvidar, asimismo, que "el Tribunal Constitucional tiene una posición institucional, definida por la autonomía y carencia de legitimidad democrática, [que] sólo posee una legitimidad constitucional orientada a un balance de poder", de ahí su competencia tasada (art. 93) y limitada a los conflictos de poder. ${ }^{90}$ Del mismo modo, el Tribunal Constitucional al "carecer de legitimidad democrática, debe deferencia a los poderes públicos democráticos, y por ende, debe contribuir a la legitimidad constitucional" del sistema político

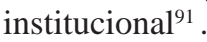

Ahora bien, si nos situamos en la perspectiva del control del art. $93 \mathrm{~N}^{\circ} 16$, hay que partir expresando que se trata de un peculiar mecanismo de control jurídico (no generalizado en el Derecho comparado, por ejemplo: Austria e Italia), ya que está controlando actos de la Administración, y cuyo objetivo de verificación es preservar la correcta distribución de competencias entre los órganos del Estado. Por ello la legitimación activa está entregada exclusivamente a las Cámaras políticas, generando una específica competencia del Tribunal Constitucional, cuya labor verificadora, que fallará de acuerdo a Derecho (art. 92), debe circunscribirse por vía de un control de atribución y abstracto.

Es de atribución el control, y como ya algo se ha adelantado sobre el particular, pues se trata de verificar si el producto normativo de la Administración (en este caso un decreto supremo) ha cumplido los límites con que la Constitución sujeta la atribución de la respectiva potestad; lógica argumentativa que inexorablemente hay que vincular, por una parte, con la posibilidades de verificación que entrega la perspectiva constitucional (esto es, de acuerdo a la competencia atributiva que se le adjudica al órgano de control y al parámetro que habilita la Carta Fundamental para llevar a cabo el juicio de conformidad con las reglas preestablecidas en ella); y, por otra parte, con el órgano legitimado para requerir (pues el interés que puede motivar al requirente

89 Hernán Hormazábal, 2006, El nuevo Tribunal Constitucional, LexisNexis, Santiago, p. 12.

90 Francisco Zúñiga, 2008, "XI Tesis acerca de la posición del Tribunal Constitucional en la Democracia Constitucional", N 88, Colección Ideas, Fundación Chile 21, p. 4.

91 Zúñiga, "XI Tesis", cit. nota n. 90, p. 7. En la doctrina nacional también se han desarrollado importantes argumentos contra la justicia constitucional en Chile y, sobre todo, en torno a la legitimidad de la justicia constitucional. Sobre el particular ver: Patricio Zapata, 2008, Justicia Constitucional. Teoría y práctica en el Derecho chileno y comparado, Santiago, Editorial Jurídica de Chile, pp. 19-62. 
La búsqueda de criterios orientadores en la configuración de las potestades normativas en Chile.

no es otro que mantener los equilibrios atributivos que la Constitución asigna a las respectivas potestades normativas, sobre todo lo concerniente a la relación ley-reglamento). Lo cual, además, no puede sino ser comprendido dentro de una clara perspectiva del control abstracto, esto es, que el Tribunal Constitucional conozca del requerimiento desvinculado de todo presupuesto concreto de aplicación del decreto supremo que se impugna (o si llegara a considerar algunos presupuestos concretos se aplicación, estos no deben ser determinantes en su argumentación constitucional), es decir, debe efectuar una confrontación abstracta y universal de la norma reglamentaria impugnada con el parámetro de la juridicidad constitucional. ${ }^{92}$

Sobre el particular, por último, hay que poner de relieve dos asuntos. Por una parte, que el origen del Tribunal Constitucional chileno en 1970, es una respuesta al fortalecimiento del régimen presidencial y tratar de resolver los conflictos constitucionales generados a raíz de la invasión de atribuciones normativas por parte del Congreso ${ }^{93}$; y, por la otra, que "los mecanismos de control de constitucionalidad tienen como fin preservar la coherencia del sistema jurídico, proveyendo así a su eficacia", esto se verifica, ya sea a través de controles abstractos, que al constatar el enfrentamiento entre las normas en conflicto evitan su aplicación simultánea, o por vía de controles de carácter concreto, a fin de superar conflictos que en el marco de un sistema jurídico se producen afectando situaciones jurídicas específicas. ${ }^{94}$ Por ello, la solución de conflictos atributivo-competenciales por parte del Tribunal Constitucional, debe discurrir en base a un control abstracto, toda vez que no resuelve un conflicto en relación a un caso particular, sino evita su aplicación simultánea de reglas eliminando la eventual norma inconstitucional que genera un conflicto atributivo; pero, como ya se ha adelantado, en ningún caso el resultado jurisdiccional puede sustituir, por "su" decisión, la norma declarada inválida.

\section{Conclusiones finales}

En este apartado se comenzarán desarrollando las principales conclusiones que corresponden a cada uno de los criterios orientadores expuestos, para luego finalizar con una conclusión general que cierra la presente indagación.

Sobre el control abstracto ver: Pedro Cruz Villalón, 1987, La formación del sistema Europeo de control de constitucionalidad (1918-1939), Madrid, Centro de Estudios Constitucionales, pp. 97-125.

93 Enrique Silva Cimma, 2008, El Tribunal Constitucional de Chile (1971-1973), Santiago, Cuadernos del Tribunal Constitucional, Número 38, pp. 21-26. Ver también: Mario Verdugo, 2003, "Notas sobre el principio de la supremacía constitucional y los decretos supremos de ejecución”, en Revista del Centro de Estudios Constitucionales, $\mathrm{N}^{\circ} 1$, pp. 387-399.

94 Carla Huerta, 2003, "La acción de inconstitucionalidad como control abstracto de conflictos normativos". Bol. Mex. Der. Comp., México, v. 36, n. 108. Disponible en: http://scielo.unam.mx/ [visitado el 20.08.2008] 
Kamel Cazor Aliste

Emilio Pfeffer Urquiaga

\section{La necesidad de desentrañar el significado de los principios de juridicidad, legalidad y reserva de ley.}

De este criterio orientador interesa destacar dos perspectivas. Por un lado, lo que usualmente se considera hoy como "principio de legalidad" administrativa, no es sólo una relación con la ley, sino con la juridicidad en su conjunto (o principio de juridicidad), tal sujeción integral determina una vinculación de la Administración con la generalidad de la juridicidad; coherentemente con ello, surge la necesidad de verificar dicho sometimiento por parte de los órganos jurisdiccionales, en el amplio plano de lo constitucionalmente adecuado. Por otro lado, el término "reserva de ley", determina dos significados distintos, uno relativo a toda la actuación administrativa y otro sólo a su potestad reglamentaria, del primero se deriva el principio de legalidad; asimismo, al ser planos de verificación y conocimiento disímiles, esta perspectiva es relevante a fin de diferenciar las cuestiones meramente legales (principio de legalidad), de los asuntos de estricta relevancia constitucional, como acontece con la vinculación entre la reserva legal y la potestad reglamentaria. En este último plano, es posible también deducir que cuando la juridicidad supone otorgar a la potestad reglamentaria igual legitimidad que la potestad legislativa en las materias que no sean objeto de reserva material de ley, la vinculación de la Administración ya no es con la generalidad de la juridicidad sino con una parte o especie de ella, que determina un específico ámbito competencial acotado negativamente por la reserva legal, donde la Administración podría ejercer legítimamente su potestad reglamentaria sin previa habilitación legal, estableciéndose, de paso, el papel que se le asigna a la ley dentro del ordenamiento. Sin embargo, como se ha visto, el papel de la reserva de ley en el Estado democrático y su ligazón con los derechos fundamentales, debilitan la intensidad de los poderes normativos de la Administración en esta esfera, cuestión que dificulta la funcionalidad normativa entre órganos que poseen legitimidad democrática, como es el caso del Congreso Nacional y el Presidente de la República.

\section{La exigencia de definir la función de la reserva legal en el Estado constitucional y democrático y su vinculación con los derechos fundamentales.}

En cuanto a este segundo criterio orientador es posible colegir que la verdadera trascendencia se centra en la intensidad (densidad normativa) de la reserva legal, lo cual debe ser entendido dentro de la heterogeneidad de manifestaciones que posibilita nuestro sistema constitucional. Dentro de este contexto, no es sostenible ni operativo, en nuestro ordenamiento constitucional, plantear una tesis basada en una idea rígida de la reserva, ya que no siempre la pérdida de intensidad o flexibilización de las leyes puede verse como un fenómeno contrario a las exigencias y rol de la reserva legal, es decir, flexibilizar no necesariamente es debilitar la reserva, ya que en la relación ley-reglamento, este último debe regular todo lo indispensable para garantizar la aplicación de la ley. Desde esta perspectiva, claramente la intensidad de la reserva se modula en función de la materia, y a mayor grado de afectación de un derecho fundamental, menos flexible serán las posibilidades de remisión de la ley al reglamento; en los 
La búsqueda de criterios orientadores en la configuración de las potestades normativas en Chile.

demás casos de reserva, el ejercicio de la potestad reglamentaria reconoce un cierto margen para introducir opciones políticas, pues la Administración, como poder legitimado democráticamente y con un claro reconocimiento constitucional de su potestad normativa, no pondría en entredicho la función de garantía de la reserva legal (paradigma liberal), ni tampoco transgrediría el pluralismo democrático (paradigma social), que son precisamente las grandes perspectivas que la fundamentan.

\section{Perspectivas del control jurídico en la relación ley-reglamento, a propósito de la verificación de las actuaciones administrativas.}

Respecto a este tercer criterio orientador es posible constatar dentro del Estadio constitucional chileno la interacción del binomio potestades normativas/sistema de control jurídico. De este modo y siguiendo el razonamiento en torno a la actuación administrativa, se debe vislumbrar, como punto de partida, la estructura de las normas que otorgan la atribución o potestad a la Administración, y luego, los límites intrínsecos del control jurídico que se deriven de aquélla; es decir, según sea la densidad de la programación legal de la actividad administrativa constitucionalmente exigida, como cuestión previa, servirá para determinar, a su vez, los límites intrínsecos del control jurídico. Criterio que resulta perfectamente coherente y aplicable con el sistema constitucional chileno, ya que la relación de la intensidad del control jurídico de la actuación administrativa respecto de la densidad de su programación jurídica, se traduce en que es el legislador quien tiene en sus manos graduar la intensidad del control jurisdiccional de la acción administrativa, según la programe con mayor o menor densidad normativa. Por ello, el estudio de los principios constitucionales, de los que depende que el legislador programe la actuación administrativa con la densidad normativa necesaria para que los jueces puedan fiscalizarla con la intensidad que consideren constitucionalmente exigida, ponen de relieve los dos principios, ya mencionados, que coexisten en nuestro ordenamiento constitucional: el principio de juridicidad (sujeción integral con la generalidad de la juridicidad) y, sobre todo, el principio de reserva de ley (sujeción con una parte o especie de la juridicidad). En el primer caso se está hablando del carácter negativo de la programación normativa, y, en el segundo, del carácter positivo de dicha programación, cuestión que determinará, en última instancia, la intensidad del control jurisdiccional, pues éste puede oscilar, dependiendo de la densidad normativa con la que el ordenamiento jurídico programe la actividad administrativa, entre un control puramente negativo, si la densidad de programación positiva es nula o insignificante, y un control perfectamente positivo, si la densidad de programación positiva es elevada. Todo ello permite diferenciar, a su vez, los dos grandes objetos del control jurídico: el control del ejercicio de las potestades administrativas y el control de su atribución; distinción que no es meramente teórica sino también de gran relevancia práctica, ya que como ocurre en el sistema de control jurídico chileno, cuando no es una misma jurisdicción la que compite en la fiscalización de la actuación administrativa, si la potestad discrecional está atribuida por ley, el juez ordinario no puede confundir el control de juridicidad de su ejercicio, que le compete a 
Kamel Cazor Aliste

Emilio Pfeffer Urquiaga

él, con el control de constitucionalidad de su atribución, pues correspondería este control, en tales casos, sobre todo a la jurisdicción que lleva a cabo el Tribunal Constitucional.

\section{Control jurídico abstracto y concreto en la competencia atributiva del Tribunal Constitucional, a propósito de la verificación de la relación ley-reglamento.}

Si nos situamos en torno a nuestro último criterio orientador desarrollado, se debe necesariamente derivar que reviste una especial importancia la perspectiva de verificación que adopte el Tribunal Constitucional cuando está involucrada la temática de la relación leyreglamento, sobre todo si se está en el plano de la solución de conflictos atributivocompetenciales, entre órganos que poseen las más relevantes potestades normativas dentro del sistema constitucional. Así, por ejemplo, el control de la constitucionalidad de los decretos supremos ha justificado, en la praxis del Tribunal Constitucional, que éste verifique su constitucionalidad en referencia a la situación concreta en que tal acto administrativo producirá sus efectos, lo que hasta ahora se ha considerado un parámetro válido de control; asunto que necesariamente obliga a centrar la atención en el ámbito e intensidad de la competencia que asume el Tribunal Constitucional para resolver dichos asuntos. A fin de dilucidar tal controversia, estimamos que el órgano jurisdiccional debe razonar en base a un control abstracto, evitando la aplicación simultánea de reglas y eliminando la norma inconstitucional que genera el conflicto atributivo. Lógica argumentativa que inexorablemente hay que vincular, por una parte, con la posibilidades de verificación que entrega la perspectiva constitucional (esto es, de acuerdo a la competencia atributiva que se le adjudica al órgano de control y al parámetro que habilita la Carta Fundamental para llevar a cabo el juicio de conformidad con las reglas preestablecidas en ella), y, por otra parte, con el órgano legitimado para requerir (pues el interés que puede motivar al requirente no es otro que mantener los equilibrios atributivos que la Constitución asigna a las respectivas potestades normativas, sobre todo lo concerniente a la relación leyreglamento).

\section{Corolario general.}

Podemos concluir, por último, que en el ámbito de las potestades normativas que configura la Constitución chilena, se estructura un sistema más teórico que real, utilizándose para ello la técnica de la reserva material de ley, como competencia de atribución del legislador, a fin de repartir el campo normativo entre ésta y el reglamento. Cuestión que, más que propiciar un sistema homogéneo y equilibrado, genera una heterogeneidad de reservas legales y una multiplicidad de combinaciones de ella, donde en su vinculación con el reglamento, además del principio de jerarquía, se requiere considerar el principio de competencia y el principio de control. De ahí que la interpretación constitucional tiene en la técnica de la reserva de ley su desafío más permanente, sobre todo en torno a la naturaleza conflictiva de las relaciones entre ley y reglamento, o la virtualidad de la controversia acerca de la extensión e intensidad de los 
poderes normativos de la Administración. Por esta razón, una visión de conjunto resulta imprescindible para valorar la funcionalidad de cada uno de los elementos que componen el sistema, pero es precisamente esa visión la que resulta más dificultosa a la hora de buscar criterios de equilibrio, cuyas posturas resultan cada vez más forzadas y difíciles de justificar. Por ello, la reserva legal no es hoy un criterio del todo funcional a la hora de fijar las relaciones entre órganos que tienen poder democrático, como son el Parlamento y el Gobierno, sobre todo frente a la falta de rigor y perfección técnica que ha demostrado el Constituyente a la hora de configurar sus ámbitos normativos.

Teniendo en cuenta esta perspectiva de razonamiento, los criterios orientadores que hemos podido deducir del entramado constitucional, solamente facilitarían soluciones parciales a la controversia de la relación ley-reglamento, con ello reconocemos una clara debilidad teóricoregulatoria en su actual configuración. De ahí que, de acuerdo a esta constatación, no sería del todo coherente seguir haciendo recaer en el Tribunal Constitucional la solución de esta difícil controversia jurídico-política. Sobre todo, como veremos en un próximo trabajo, cuando de la doctrina jurisprudencial que ha desarrollado hasta ahora el Tribunal -a propósito de esta temática-, no se vislumbran en su razonamiento sólidas premisas teórico-constitucionales, como criterios orientadores, que permitan solucionar con claridad este trascendental asunto competencial y configurador de las potestades normativas. 
228 Revista IUs et PraXis - AÑo 15 - № 1 